\title{
Dynamic Adjustment in a Numerically Simulated Mesoscale Convective System: Impact of the Velocity Field
}

\author{
Ernani de Lima Nascimento* and Kelvin K. Droegemeier \\ School of Meteorology, and Center for Analysis and Prediction of Storms, University of Oklahoma, Norman, Oklahoma
}

(Manuscript received 13 December 2004, in final form 14 December 2005)

\begin{abstract}
An identical twin methodology is applied to a three-dimensional cloud model to study the dynamics of adjustment in deep convective storms. The principal goal is to diagnose how mass and velocity fields mutually adjust in order to better understand the relative information content (value) of observations, the physical interdependency among variables, and to help in the design of dynamically consistent analyses to ensure smooth startup of numerical prediction models.

Using a control simulation ("truth" or "nature" run) of an idealized long-lived bow echo convective system, a series of adjustment experiments is created by resetting, in various combinations, the horizontal and vertical velocity components of the control run to their undisturbed base state values during the mature stage of storm system evolution. The integrations then are continued for comparison against the control. This strategy represents a methodology for studying transient response to an impulsive perturbation in a manner conceptually similar to that used in geostrophic and hydrostatic adjustment.

The results indicate that resetting both horizontal velocity components alters the character of the convection and slows considerably the overall storm system evolution. In sharp contrast, when only the vertical velocity component is reset, the model quickly restores both updrafts and downdrafts to nearly their correct (control run) values, producing subsequent storm evolution virtually identical to that of the control run. Other combinations yield results in between these two extremes, with the cross-line velocity component proving to be most important in restoration toward the control run. This behavior is explained by acoustic adjustment of the pressure and velocity fields in direct response to changes in velocity divergence forced by the withdrawal of wind information.
\end{abstract}

\section{Introduction}

During the past several years, the specification in relatively simple cloud models of both the environment and inner structure of observed convective storms has received a great deal of attention (e.g., Crook and Tuttle 1994; Shapiro et al. 1995; Sun and Crook 1998, 2001; Ducrocq et al. 2000; Weygandt et al. 2002a,b; Crook and Sun 2002, 2004), as has the sensitivity of simulated storm evolution to certain meteorological fields or features (e.g., Yang and Houze 1995b; Crook

\footnotetext{
* Current affiliation: Laboratório de Estudos em Monitoramento e Modelagem Ambiental, Instituto Tecnológico SIMEPAR, Curitiba, Brazil.
}

Corresponding author address: Dr. Ernani L. Nascimento, Instituto Tecnológico SIMEPAR, Centro Politécnico da UFPR, Caixa Postal 19100, Curitiba/PR, CEP. 81531-990, Brazil.

E-mail: elnascimento@ufpr.br
1996; Gilmore and Wicker 1998; Park and Droegemeier 2000; McCaul and Cohen 2002) and model initial conditions (e.g., McPherson and Droegemeier 1991; Droegemeier and Levit 1993; Li et al. 1995; Ducrocq et al. 2000; Elmore et al. 2002). Building upon this work and following a 50-year history of operational forecasting (e.g., Kalnay 2003), initialization procedures now are being developed for nonhydrostatic, full-physics cloud-resolving models, particularly for application to deep convection (e.g., Gao et al. 2001; Brewster 2003a,b; Xue et al. 2000, 2001, 2003).

The explicit prediction of storm-scale weather, which nominally connotes model grid spacings of $3 \mathrm{~km}$ or less and the representation of discrete updrafts and downdrafts in the context of deep convection, usually requires observations on the same spatial scale. ${ }^{1}$ The only

\footnotetext{
${ }^{1}$ An exception exists in cases of strong forcing, for example, terrain, fronts, and coastal zones.
} 
observing system presently capable of providing such data routinely over large volumes of the atmosphere is the Weather Surveillance Radar-1988 Doppler [(WSR88D), Next Generation Weather Radar (NEXRAD)]. Unfortunately, because scans from adjacent radars in the national WSR-88D network overlap mostly at long range, multiple-Doppler winds at fine scales rarely are available. Thus, considerable attention has been given during the past 15 years toward the retrieval of threedimensional velocity, thermodynamic and microphysical information from time series volume scans of singleDoppler radial wind, reflectivity, and spectrum width data (e.g., Ziegler 1985, 1988; Sun et al. 1991; Laroche and Zawadzki 1994; Crook and Tuttle 1994; Shapiro et al. 1995; Qiu and Xu 1996; Sun and Crook 1997, 1998, 2001; Gao et al. 2001; Lazarus et al. 2001; Weygandt et al. 2002a,b). Techniques developed to date span a broad spectrum of theoretical complexity and computational cost, with new ensemble-based approaches showing notable promise (e.g., Snyder and Zhang 2003; Dowell et al. 2004; Zhang et al. 2004; Tong and Xue 2005; Xue et al. 2006).

Despite this large body of work, little effort has been expended to understand which variables actually are needed to obtain a quality storm-scale forecast, their associated accuracy requirements, or the degree and manner in which errors in one field can influence other fields. These issues are especially important in variational data assimilation, where the topology of the cost function depends upon the number and nature of the control variables, and where error covariances are fundamental to the overall impact of observations. Consequently, we seek in this study to address a number of fundamental questions about the dynamic interplay and mutual adjustment among dependent meteorological variables in a forecast model, principally, though not limited to, the following:

- Which variables are most important for explicitly predicting the evolution of an existing convective system?

- To what extent do variables at the storm-scale contain redundant information?

- How do errors in one atmospheric field at the stormscale affect other fields, and what dynamics governs their mutual response/adjustment?

Using an identical twin approach with a control simulation ("truth" or "nature" run) of an idealized longlived bow echo convective system, we conduct a number of dynamic adjustment experiments in which the horizontal and vertical velocities of the control simulation are reset, in various combinations, to their undis- turbed base state values during the mature stage of storm system evolution. The restarted integrations then are compared against the control solution. This strategy is not meant to represent a realistic initialization procedure for a forecast model, but rather a methodology for studying transient response in a manner conceptually similar to that used in geostrophic adjustment. Our principal goal is to diagnose how the mass and velocity variables adjust to the imposed loss of kinematic information within the storm, with the end state, in contrast to geostrophic adjustment, being nonsteady and subject to no known balance relations. In subsequent papers we will describe the impact of withdrawing thermodynamic and microphysical information alone, and in combination with the wind fields, as well as extension of the current results to other modes of convection.

The next section provides a brief review of atmospheric adjustment theory and its relationship to the present work. Section 3 describes the experiment design, while the control simulation is presented in section 4. Results and discussion of the adjustment experiments are presented in sections 5 and 6 , while section 7 offers a summary and recommendations for future research.

\section{Atmospheric adjustment}

The atmospheric state described by a given meteorological variable may constrain the behavior of one or more other variables, while particular quantities may contain information that is redundant. Consequently, an understanding of the manner in which atmospheric variables mutually interact has proven extremely useful in atmospheric dynamics and especially in numerical weather analysis and prediction (e.g., Smagorinsky et al. 1970; Daley 1991). For example, based on geostrophic adjustment theory, Charney et al. (1969) sought to assess the impact of satellite-derived temperature observations on the initialization of a global circulation model under the assumption that temperature and pressure are related hydrostatically. Using simulated data, they found that the large-scale wind field may be inferred from a pseudo-satellite-derived temperature profile if surface pressure is known, and that inserting temperature corrections into a model at 12-h intervals can significantly improve the forecast. In other words, high-accuracy wind observations were not required at the scale considered provided that temperature was known.

Although no simple balance relations exist among the wind and mass fields on the storm scale apart from 


\section{LARGE-SCALE DYNAMIC (GEOSTROPHIC) ADJUSTMENT}

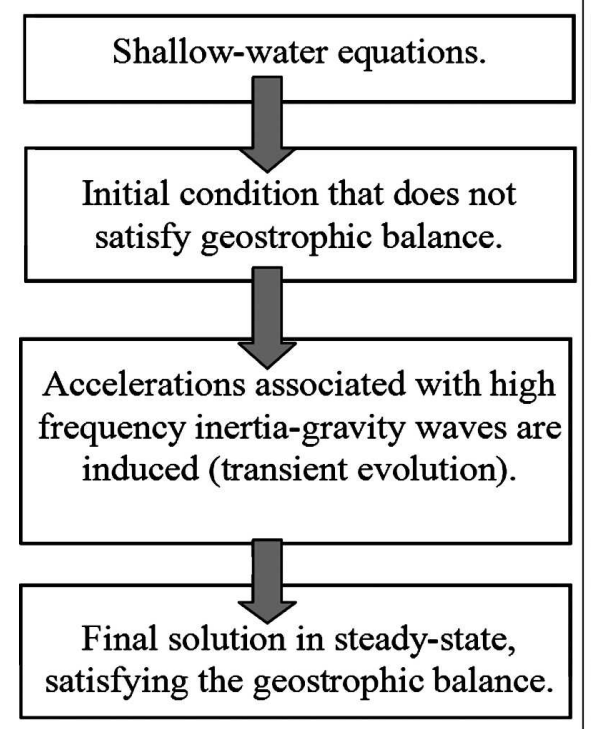

CONVECTIVE SCALE DYNAMIC ADJUSTMENT

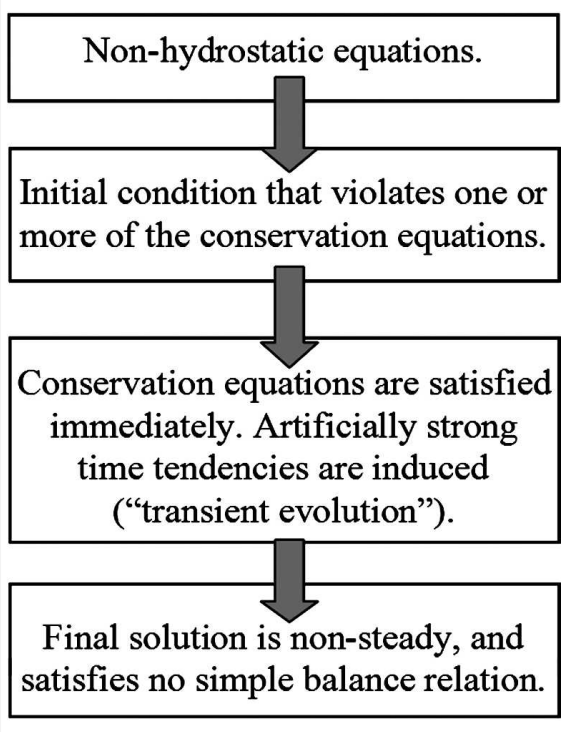

FIG. 1. Comparison between large-scale (geostrophic) and convective-scale dynamic adjustment.

mass continuity, ${ }^{2}$ investigations of geostrophic adjustment (e.g., Blumen 1972), hydrostatic adjustment (e.g., Bannon 1995), and convectively induced gravity and compression waves (e.g., Bretherton and Smolarkiewicz 1989; Nicholls et al. 1991; Mapes 1993; Pandya and Durran 1996; Nicholls and Pielke 1994a,b, 2000; Fovell 2002) provide a solid foundation upon which to build. In geostrophic and hydrostatic adjustment, an unbalanced initial condition leads to a transient wave response that eventually establishes a steady-state balance among the mass and wind fields.

Bannon (1995) revisited the problem of the linear response of an isothermal atmosphere to a horizontally homogeneous impulsive heating source, originally addressed by Lamb (1908, 1932). For his idealized case, Bannon (1995) found that hydrostatic adjustment is realized by vertically propagating high-frequency sound waves excited at the top and bottom of the instantaneously heated layer. With time, the oscillatory regime approaches the acoustic cutoff frequency, meaning that

\footnotetext{
${ }^{2}$ Cyclostrophic flow, which is a form of balanced dynamics, is mostly restricted to tornadic vortices (e.g., Davies-Jones et al. 2001), which represent a scale smaller than considered here. Long-lived mesoscale convective vortices, on the other hand, approach the definition of a balanced flow (Davis and Weisman 1994), but such features do not account for the maintenance of the entire convective system that generated them.
}

no high-frequency acoustic mode remains in the domain of a steady-state solution in hydrostatic balance. Later studies by Sotack and Bannon (1999), van Delden (2000), Nicholls and Pielke (2000), Chagnon and Bannon (2001), and Duffy (2003) addressed the hydrostatic adjustment problem in more realistic situations.

In storm-scale dynamic adjustment, the impulsive perturbation of one or more dynamic, thermodynamic, or microphysical fields within a time-evolving flow instantaneously violates the full governing equations, also creating a transient response. In this case, however, the end result is not a steady solution but rather a timeevolving one within which the equations again are satisfied via mutual adjustment among all fields. Figure 1 summarizes the conceptual relationship between largescale and storm-scale dynamic adjustment.

Fiedler (2002) studied the response of a compressible, nonhydrostatic model initialized with wind fields that violate anelastic mass continuity. He showed that the imposition of a vertical velocity field, like that associated with a convective storm, without a concomitant adjustment to the horizontal velocity results mostly in the generation of acoustic waves that have little impact on the physically relevant convective circulation. He found that if the horizontal velocity is to respond to initial vertical motion, the characteristic length scale of the former should be much smaller than that of the 
latter (high aspect ratio). Conversely, if the aspect ratio is low, the amplitude of the vertical velocity is reduced during acoustic adjustment, which is equivalent to saying that the vertical velocity responds to the horizontal component of the flow initially specified.

Although Fielder's analysis provides important insight into dynamic adjustment for a simple, 2D dry convective flow, real convective systems are far more complex and not amenable to representation by the steady Fourier modes used by Fiedler (e.g., Yang and Houze 1995a; Pandya and Durran 1996; Fovell 2002). These considerations point to some complicating factors when defining the effective aspect ratio of deep convective storms, and we investigate them in the experiments that follow.

\section{Model configuration and experiment design}

We use version 4.5 .1 of the nonhydrostatic and fully compressible Advanced Regional Prediction System (ARPS; described in Xue et al. 2000, 2001, 2003) to generate a 6-h control simulation (hereafter CNTRL) of an idealized bow echo. Similar to Weygandt et al. (1999), a series of adjustment experiments is then conducted, using exactly the same model configuration as in CNTRL, by restarting CNTRL at $4 \mathrm{~h}$-during the mature stage of the simulated bow echo mesoscale convective system (MCS) - at which time we artificially reset selected components of the velocity field to their undisturbed base state values (equivalent to withdrawing the velocity perturbation). Thus, all tendency and forcing terms that contain the associated velocity perturbation fields in the model equations are set to zero at restart time and all other fields remain unchanged.

The withdrawal experiments are shown in Table 1. For example, in experiment RESET_UV, we set terms such as $\partial \mathbf{V}_{H}^{\prime} / \partial t$ and $\mathbf{V}_{H}^{\prime} \cdot \boldsymbol{\nabla} p^{\prime}$ to zero, where $\mathbf{V}_{H}^{\prime}$ is the perturbation horizontal velocity, whereas in RESET_W, terms such as $\partial w / \partial t$ and $\rho g w$ are set to zero. In this manner the model equations retain no "memory" of the quantities reset though other dependent variables obviously do. The withdrawal simulations are integrated for two hours and compared to the last two hours of CNTRL, as summarized in Fig. 2. No errors are added to any of the fields.

All simulations are conducted in a three-dimensional domain of size $284 \times 356 \times 18.2 \mathrm{~km}^{3}$ with uniform horizontal and vertical grid spacings of $2 \mathrm{~km}$ and $400 \mathrm{~m}$, respectively. The background environment, or undisturbed base state, is horizontally homogeneous, with vertical temperature and moisture profiles following the Weisman and Klemp (1982) idealized sounding (their Fig. 1). This sounding has a surface water vapor
TABLE 1 . Summary of the experiments.

\begin{tabular}{ll}
\hline \hline Experiment & \multicolumn{1}{c}{$\begin{array}{c}\text { Variable being reset to the } \\
\text { unperturbed base state }\end{array}$} \\
\hline RESET_W & $\begin{array}{l}\text { Vertical velocity } \\
\text { RESET_UV }\end{array}$ \\
HESET_U & $\begin{array}{l}\text { Zonal component of the velocity } \\
\text { Reridional component of the velocity }\end{array}$ \\
RESET_V & $\begin{array}{l}\text { Zonal and vertical components of the velocity } \\
\text { RESET_UW }\end{array}$ \\
RESET_VW & $\begin{array}{l}\text { Meridional and vertical components of the } \\
\text { velocity }\end{array}$ \\
&
\end{tabular}

mixing ratio of $14 \mathrm{~g} \mathrm{~kg}^{-1}$, surface-based convective available potential energy (CAPE) of $2300 \mathrm{~J} \mathrm{~kg}^{-1}$, and convective inhibition (CIN) of $28 \mathrm{~J} \mathrm{~kg}^{-1}$. The wind profile is that used by Weisman (1993) in his moderate shear bow echo case, with a unidirectional westerly vertical shear of $1 \times 10^{-2} \mathrm{~s}^{-1}$ confined to the first $2.5 \mathrm{~km}$ and constant $25 \mathrm{~m} \mathrm{~s}^{-1}$ winds above.

In CNTRL, convection is initiated by a single semielliptical thermal impulse of dimension $10.0 \times 10.0 \times 1.4$ $\mathrm{km}^{3}$ with a maximum perturbation of $+2 \mathrm{~K}$. The impulse is centered at $(x, y, z)=(116.0,178.0,1.5) \mathrm{km}$ (the midpoint of the north-south extent of the model domain). The analytic formulation for the thermal is the same as that given by Eqs. (4.1) and (4.2) of Klemp and Wilhelmson (1978). The Coriolis force is included, and a steady base state that does not evolve toward thermal wind balanced is imposed by subtracting the geostrophically balanced pressure gradient from the horizontal momentum equations. Thus, the Coriolis force acts only on wind perturbations, avoiding imposition of a meridional temperature gradient that would modify the lower levels of the background sounding (Klemp and Wilhelmson 1978; Richardson 1999) and induce a spatial bias in convective activity that is undesirable in this idealized study.

No surface or radiation physics is used and water species are parameterized using the Lin et al. (1983) cloud microphysics scheme, which includes conservation equations for cloud ice $\left(q_{i}\right)$, snow $\left(q_{s}\right)$, and hail $\left(q_{h}\right)$ mixing ratios in addition to water vapor $\left(q_{v}\right)$, cloud water $\left(q_{c}\right)$, and rainwater $\left(q_{r}\right)$ mixing ratios. A small time step (for acoustic terms) of $1 \mathrm{~s}$ and a big time step (for advection and forcing terms) of $4 \mathrm{~s}$ are used. Subgridscale turbulence is parameterized with a 1.5 -order turbulent kinetic energy closure scheme. Radiation lateral and top (Klemp and Durran 1983; Durran 1999) boundary conditions are employed, along with a rigid free-slip bottom boundary condition. A divergence damping term is included in the momentum equations to attenuate acoustic modes (Xue et al. 2000). A summary of key model parameters is shown in Table 2. 


\section{CONTROL SIMULATION}

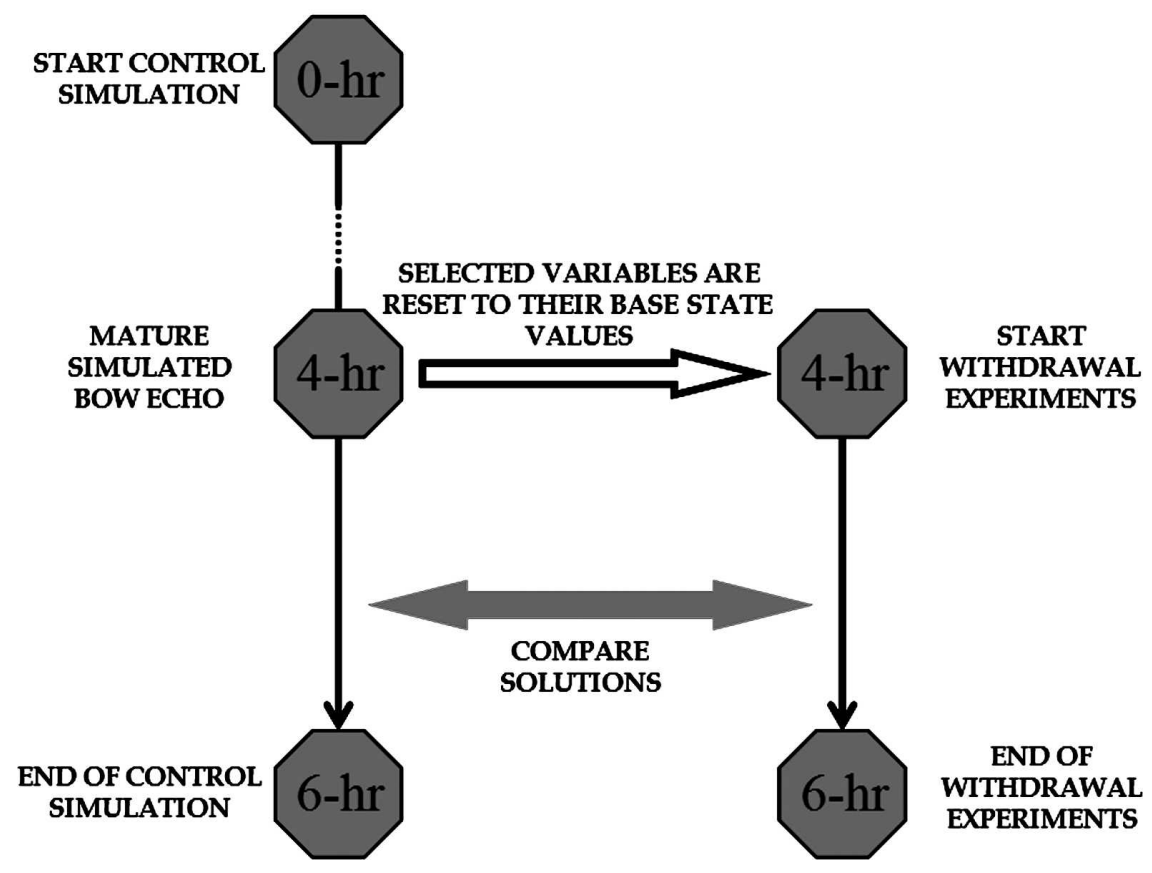

FIG. 2. Experiment methodology, where a 6-h simulation of a bow echo [control simulation (CNTRL)] is followed by a series of withdrawal experiments in which selected variables are reset to their unperturbed base state values at $4 \mathrm{~h}$ (mature stage of the MCS). Each withdrawal experiment produces a 2-h "forecast," the evolution of which from 4 to $6 \mathrm{~h}$ is examined and compared with CNTRL.

Strictly speaking, the lateral boundary conditions of all withdrawal experiments should be forced at each time step by the solution from CNTRL. For computational simplicity this is avoided, under the assumption that the 2-h prediction time (i.e., from 4 to $6 \mathrm{~h}$ ) is sufficiently short, and that the region of interest is sufficiently removed from the lateral boundaries, to minimize any associated effects.

\section{Control simulation}

We chose to examine a bow echo MCS in this study because it often displays coherent mesoscale structure for several hours [such as a strong surface cold pool, mesoscale convective vortices (MCVs), and rear-inflow jets (RIJs); e.g., Przybylinski 1995; Wakimoto 2001; Weisman 2001], even in situations of weak synoptic forcing (Johns 1993) and even though individual convective elements within the system have relatively short lifetimes. At $4 \mathrm{~h}$ (the time at which the withdrawal experiments are initiated) in CNTRL (Figs. 3a,b), the simulated MCS displays characteristics of a broken

\section{WITHDRAWAL EXPERIMENTS}


TABLE 2. Physical and computational parameters used in the numerical simulations.

\begin{tabular}{|c|c|c|}
\hline Parameter & Symbol & Value \\
\hline Horizontal grid spacing & $\Delta x, \Delta y$ & $2000 \mathrm{~m}$ \\
\hline Vertical grid spacing & $\Delta z$ & $400 \mathrm{~m}$ \\
\hline Large time step & $\Delta t$ & $4 \mathrm{~s}$ \\
\hline Small time step & $\Delta \tau$ & $1 \mathrm{~s}$ \\
\hline Coriolis parameter & $f$ & $0.7 \times 10^{-4} \mathrm{~s}^{-1}$ \\
\hline Turbulent Prandtl number & $K_{m} / K_{H}$ & 0.47 \\
\hline $\begin{array}{l}\text { Fourth-order horizontal } \\
\text { mixing coefficient }\end{array}$ & $K_{4}$ & $1.25 \times 10^{10} \mathrm{~m}^{4} \mathrm{~s}^{-1}$ \\
\hline \multicolumn{3}{|l|}{ Divergence damping coefficient: } \\
\hline horizontal & $\alpha_{h}$ & $2.0 \times 10^{5} \mathrm{~m}^{2} \mathrm{~s}^{-1}$ \\
\hline vertical & $\alpha_{v}$ & $8.0 \times 10^{3} \mathrm{~m}^{2} \mathrm{~s}^{-1}$ \\
\hline $\begin{array}{l}\text { Second-order vertical mixing } \\
\text { coefficient }\end{array}$ & $K_{2}$ & $120 \mathrm{~m}^{2} \mathrm{~s}^{-1}$ \\
\hline Microphysics & \multicolumn{2}{|c|}{ Six-category liquid and ice } \\
\hline Lateral boundary conditions & \multicolumn{2}{|c|}{ Open to gravity waves } \\
\hline Top boundary conditions & \multicolumn{2}{|c|}{ Open to gravity waves } \\
\hline Turbulence parameterization & \multicolumn{2}{|c|}{$\begin{array}{l}\text { Anisotropic } 1.5 \text {-order } \\
\text { TKE closure }\end{array}$} \\
\hline Bottom boundary conditions & \multicolumn{2}{|c|}{ Rigid free slip } \\
\hline $\begin{array}{l}\text { Horizontal and vertical } \\
\text { advection }\end{array}$ & \multicolumn{2}{|c|}{ Fourth order } \\
\hline \multicolumn{3}{|l|}{$\begin{array}{l}\text { Initial thermal perturbation } \\
\text { (CNTRL only) }\end{array}$} \\
\hline Magnitude & $\Delta \Theta$ & $2.0 \mathrm{~K}$ \\
\hline Horizontal radius & $x_{r}, y_{r}$ & $10000 \mathrm{~m}$ \\
\hline Vertical radius & $z_{r}$ & $1400 \mathrm{~m}$ \\
\hline $\begin{array}{l}\text { Height of center above } \\
\text { ground }\end{array}$ & $z_{c}$ & $1500 \mathrm{~m}$ \\
\hline
\end{tabular}

similarity with results presented by Weisman (1993), reveal features characteristic of a mature squall line with embedded bow echoes, for example, a strong upright updraft $\left(22 \mathrm{~m} \mathrm{~s}^{-1}\right)$ just above the leading edge of the advancing cold pool, positive thermal perturbations at midlevels associated with latent heating, and a welldeveloped mesolow above the cold pool containing strong negative pressure perturbations $(-200 \mathrm{~Pa})$ below the region of strongest midlevel warming. The mesolow generates a west-to-east pressure gradient acceleration that plays an important role in creating the RIJ.

As the integration proceeds, the cold pool continues to spread and at $6 \mathrm{~h}$ it covers the entire meridional extent of the domain (Fig. 3c). The simulated MCS moves mostly eastward at approximately $22 \mathrm{~m} \mathrm{~s}^{-1}$ from 4 to $5 \mathrm{~h}$, and at $26 \mathrm{~m} \mathrm{~s}^{-1}$ from 5 to $6 \mathrm{~h}$. Two regions of strong and widespread surface outflow are evident during the final 2-h period: one in the center of the domain, associated with a well-defined mesohigh, and a second farther south, approaching the southern boundary (Fig. $3 c)$. Another striking feature is a dominant low- to midlevel cyclonic MCV at the northern end of the largest bow echo (Fig. 3d) - a pattern often observed in asymmetric MCSs (Houze 1993). Our attention hereaf- ter will be restricted to the center of the domain because the south and north ends of the MCS are close to the lateral boundaries.

\section{Results}

\section{a. Overview}

The results at $6 \mathrm{~h}$ (i.e., after a 2-h simulation) in RESET_W are shown in Figs. 4a,b. This solution bears a striking resemblance to that of CNTRL (cf. with Figs. $3 \mathrm{c}, \mathrm{d})$. Not only is the proper convective mode maintained, but all key mesoscale features of CNTRL are present, indicating that the withdrawal at $4 \mathrm{~h}$ of the vertical motion field (both updrafts and downdrafts) has little impact. The results for RESET_UV (Figs. $4 c, d)$, however, are dramatically different. The simulated MCS does not maintain a bow echo structure, at least within the 2-h integration period being considered. The strong MCV generated in CNTRL is absent, and the strengths of the surface cold pool, mesohigh, and outflow are significantly reduced. These results agree in general with those of Weygandt et al. (1999) for a numerically simulated supercell, though their study did not provide a physical explanation.

The vertical cross sections in Fig. 5 provide a close-up view of the flow field, along the apex of the main bow echo segment, shortly after restart for CNTRL, RESET_W, and RESET_UV. Evident is a rapid regeneration (weakening) of the correct vertical motion in RESET_W (RESET_UV). However, the cross sections alone, shown with equivalent spacing in both coordinate directions, do not indicate an unambiguously low aspect ratio for the features depicted, as would be expected from Fiedler's (2002) analysis. In fact, the aspect ratios are near unity, with the flow changing from updrafts to downdrafts in vertical and horizontal scales of roughly the same order. Hence, an approach different from that of Fiedler (2002) is used below to understand dynamic adjustment in the present simulations.

\section{b. Analysis of the pressure equation}

In RESET_W, horizontal divergence is present at restart time because the horizontal velocities are unaltered; in RESET_UV, however, the horizontal flow is completely modified. Thus, in the very early evolution of RESET_W (RESET_UV) following restart, dynamic adjustment occurs among the initially unperturbed pressure field, the perturbed vertical (horizontal) velocity, and the unperturbed horizontal (vertical) velocity. To understand these interactions, consider 

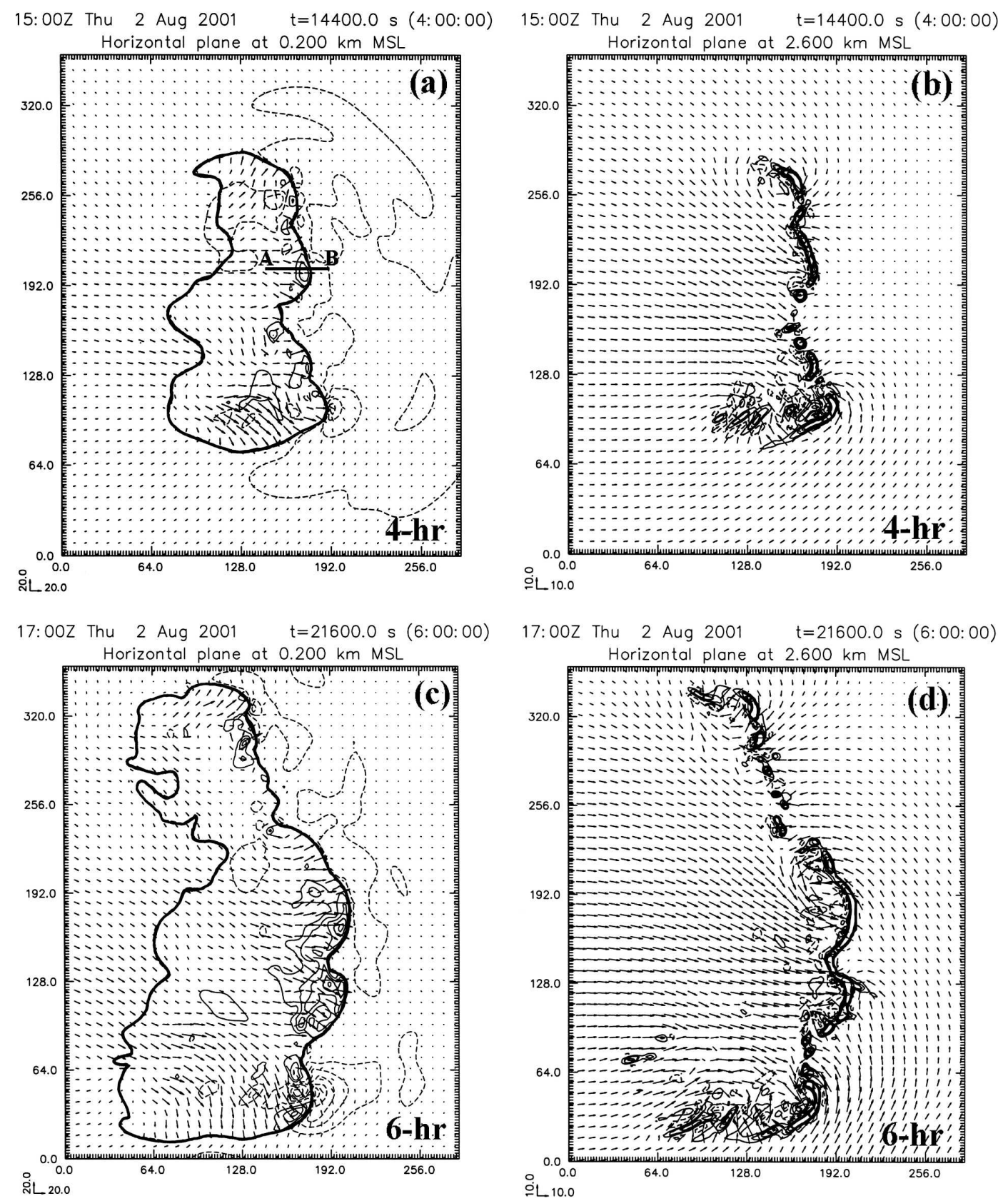

FIG. 3. CNTRL at (a), (b) $t=4 \mathrm{~h}$ and (c), (d) $t=6 \mathrm{~h}$ at altitudes of (a), (c) $z=200 \mathrm{~m}$ and (b), (d) $z=2600 \mathrm{~m}$. Thick solid lines in (a) and (c) denote the $-2 \mathrm{~K}$ potential temperature perturbation contour indicating the boundary of the cold pool; pressure perturbation contours at 100-Pa intervals are indicated by thin solid (positive) and dashed (negative) lines. Ground-relative winds are shown as vectors. In (b) and (d), contours of vertical velocity are indicated at $2 \mathrm{~m} \mathrm{~s}^{-1}$ intervals, with solid (dashed) lines representing updrafts (downdrafts). Stormrelative wind vectors are also shown. A domain translation of $u=22 \mathrm{~m} \mathrm{~s}^{-1}$ is applied at $4 \mathrm{~h}$, with a translation of $v=-1.67 \mathrm{~m} \mathrm{~s}^{-1}$ added at $5 \mathrm{~h}$.

the prognostic equation for perturbation pressure $p^{\prime}$, given by

$$
\frac{\partial p^{\prime}}{\partial t}=\bar{\rho} g w-\mathbf{V} \cdot \nabla p^{\prime}-\rho c_{s}^{2} \boldsymbol{\nabla} \cdot \mathbf{V}+\rho c_{s}^{2} \frac{1}{\theta} \frac{D \theta}{D t},
$$

where $\bar{\rho}$ is the base state density that is a function only of height, $\rho$ is the total density, $g$ is the acceleration due to gravity, $\mathbf{V}$ is the three-dimensional velocity vector, and $c_{s}$ is the speed of sound. Equation (1) essentially is the pressure equation solved by ARPS except that the 

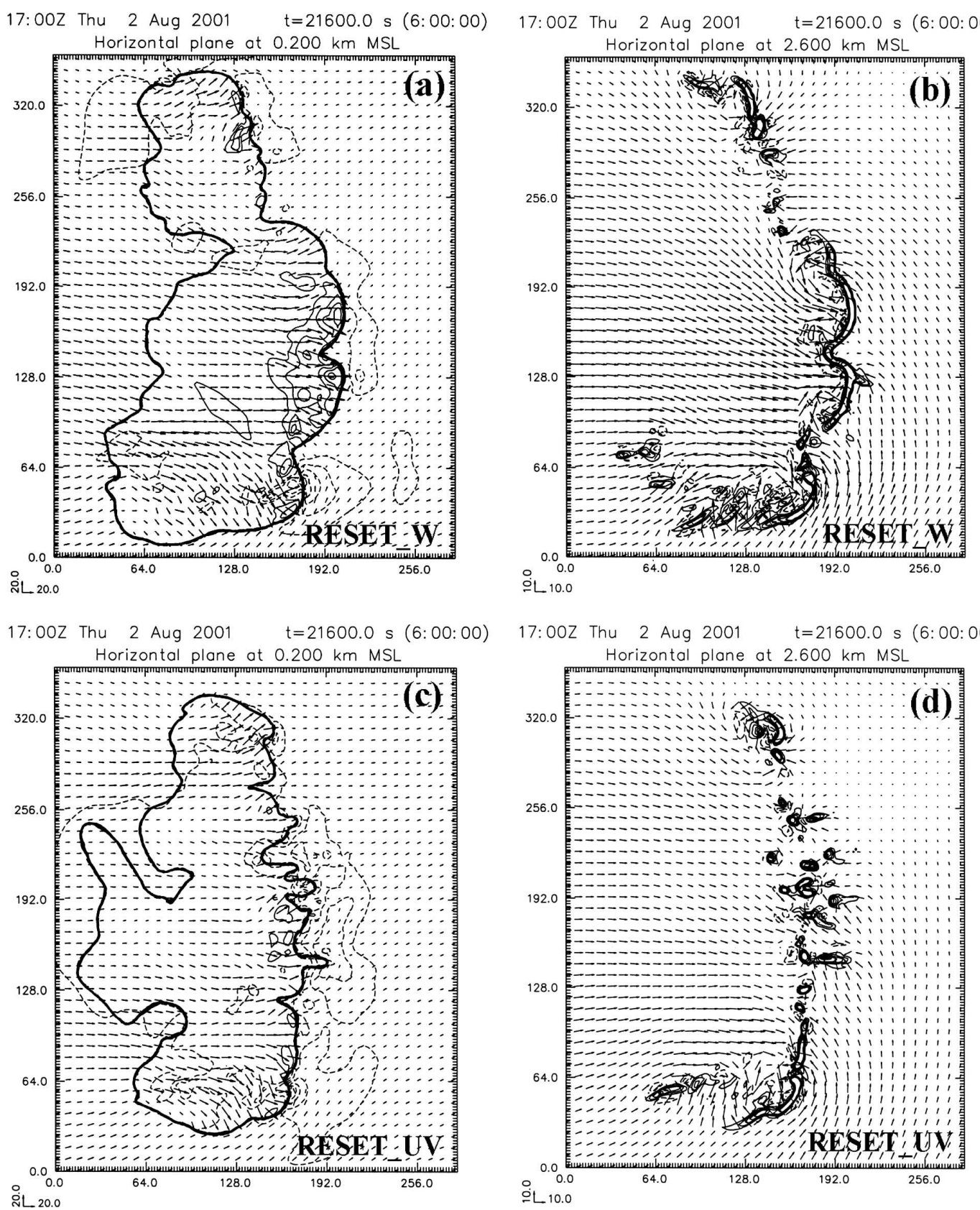

FIG. 4. Same as in Fig. 3, but for experiments (a), (b) RESET_W and (c), (d) RESET_UV at $t=6 \mathrm{~h}$ (i.e., after $2 \mathrm{~h}$ of integration).

last term, representing contributions from diabatic heating and changes in water vapor, is dropped given its typically small magnitude relative to other terms (see Xue et al. 2000 for further details).

We evaluate the relative magnitude of each of the first three forcing terms in Eq. (1) by comparing the associated fields at $t=4 \mathrm{~h}$ in CNTRL, as indicated in Fig. 6 (for the same vertical cross section examined in Fig. 5). The vertical advection of base state pressure $(\bar{\rho} g w)$ and the velocity divergence $\left(-\rho c_{s}^{2} \boldsymbol{\nabla} \cdot \mathbf{V}\right)$ are comparable in order of magnitude, but with the latter displaying larger values (note the different contour intervals). The advection of perturbation pressure $\left(-\mathbf{V} \cdot \nabla p^{\prime}\right)$ is two orders of magnitude smaller. Compared to divergence, the $\bar{\rho} g w$ term plays a secondary role, as will be shown later. Hereafter, we focus on the analysis of the divergence term. 
$4 \mathrm{hr} 00 \mathrm{~min} 00 \mathrm{~s}$
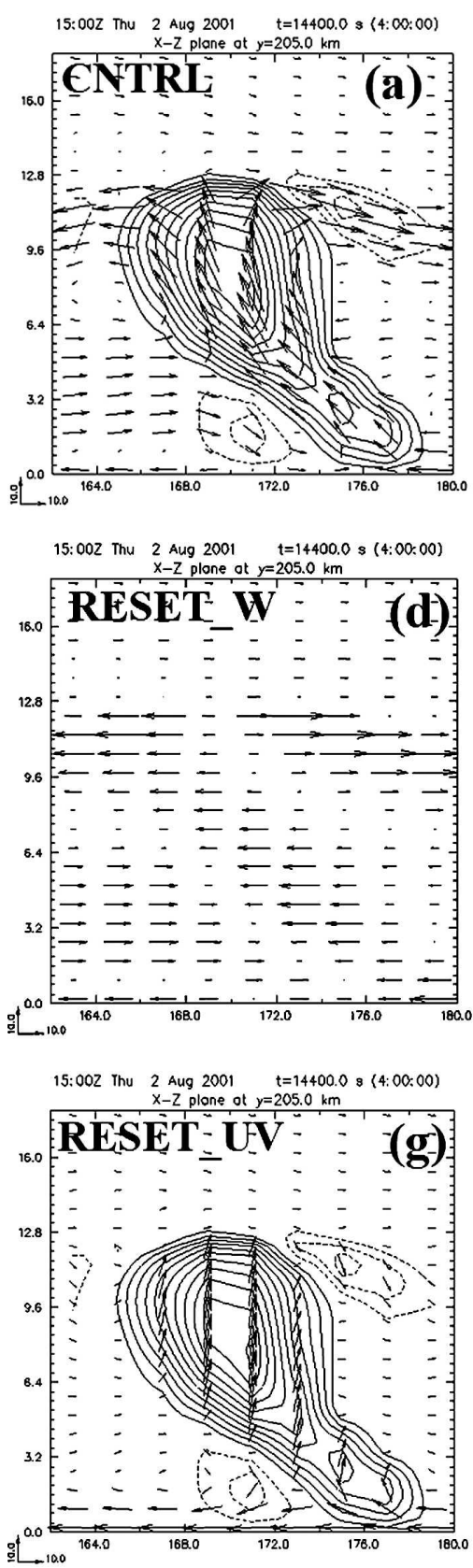

$4 \mathrm{hr} 01 \mathrm{~min} 04 \mathrm{~s}$
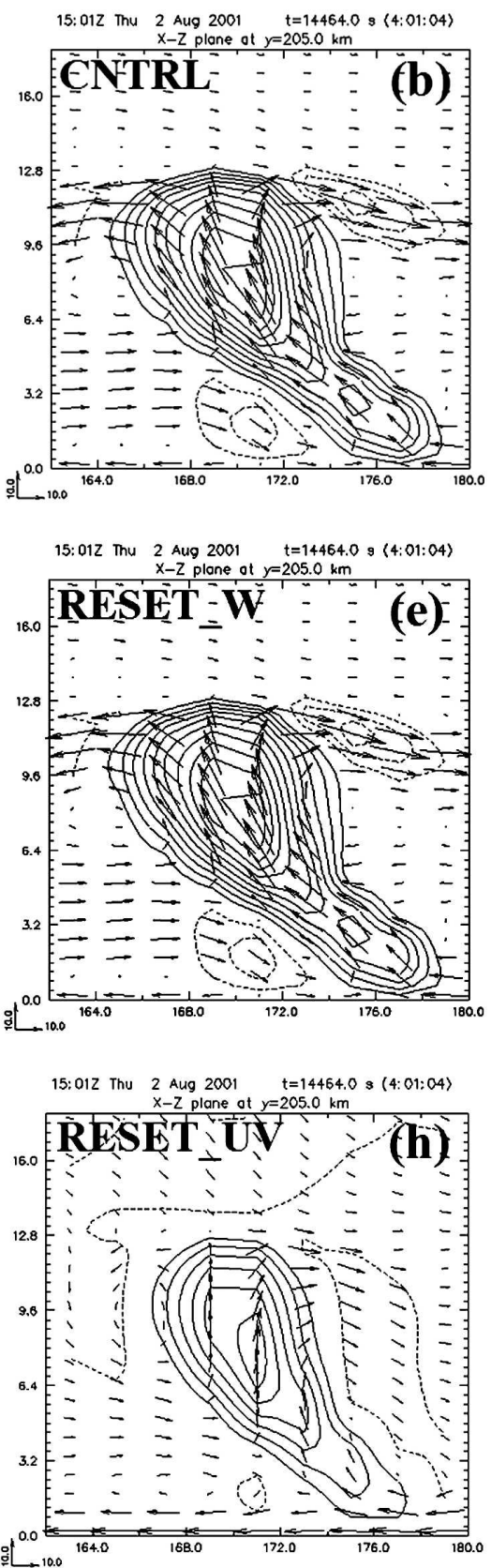

4 hr 10 min $00 \mathrm{~s}$
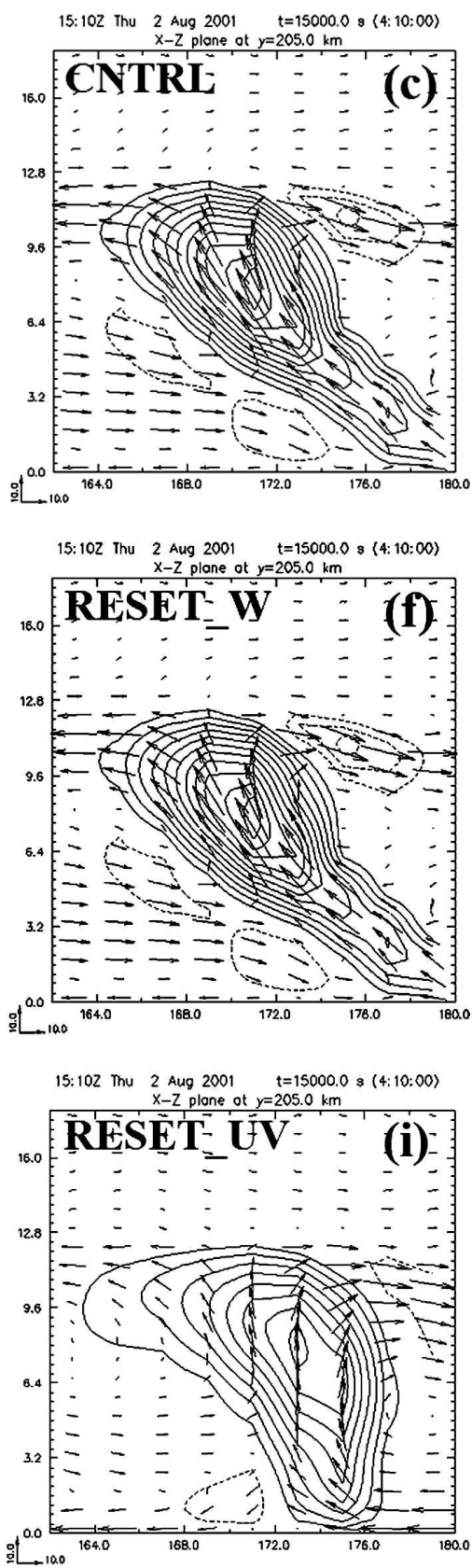

FIG. 5. Vertical cross sections in the $x-z$ plane along $y=205 \mathrm{~km}$ (same $y$ coordinate of segment AB in Fig. 3a) for the storm-relative motion field. The domain shown is $18 \mathrm{~km} \times 18 \mathrm{~km}$, and vertical velocity is contoured at $2 \mathrm{~m} \mathrm{~s}^{-1}$ intervals with the zero contour omitted. Solid (dashed) lines are updrafts (downdrafts). Storm-relative velocity vectors are plotted at every other vertical grid point. (a), (d), (g) $t=4 \mathrm{~h}$ (initial conditions for withdrawal experiments); (b), (e), (h) $t=1 \mathrm{~min}, 4 \mathrm{~s}$ following restart; and (c), (f), (i) $t=10 \mathrm{~min}$ following restart.

The 3D velocity divergence can be written as follows:

$$
\boldsymbol{\nabla} \cdot \mathbf{V}=\nabla_{H} \cdot \mathbf{V}+\partial w / \partial z
$$

Consider the upward branch of an idealized convective cell (Fig. 7) in which the return circulation is weak and distributed over a large area. Regions 1 and 2 indicate the top and bottom of the updraft, respectively, with the former representing the tropopause and the latter ground level. In region $1, \nabla_{H} \cdot \mathbf{V}>0$ and $\partial w / \partial z<0$, while in region $2, \nabla_{H} \cdot \mathbf{V}<0$ and $\partial w / \partial z>0$. In 

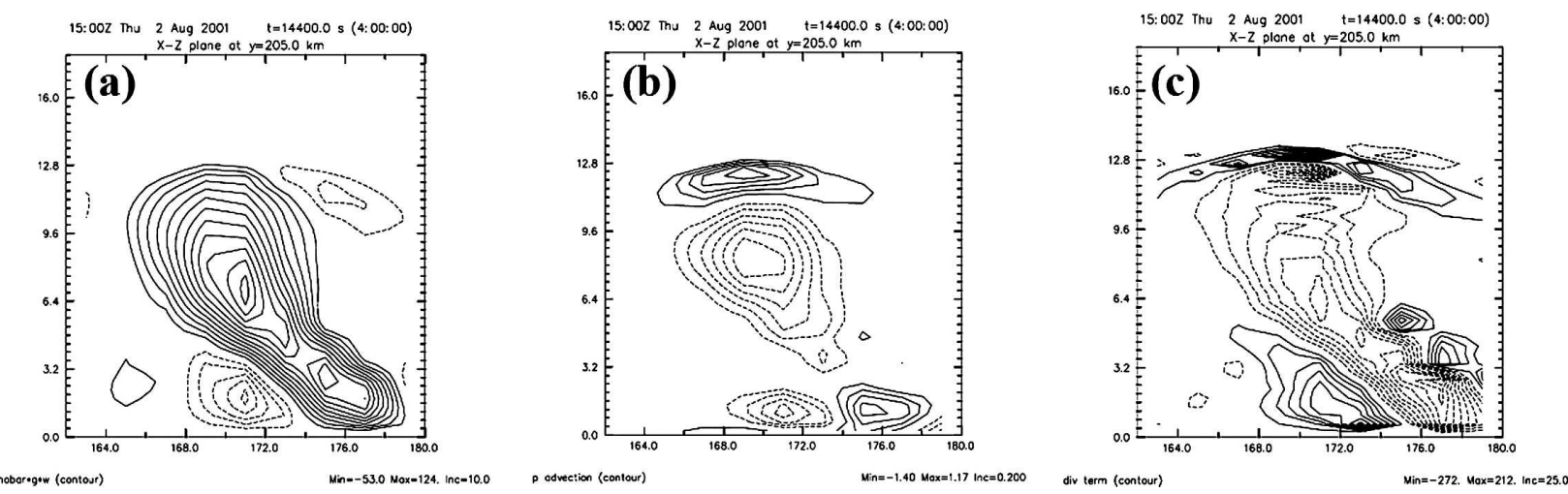

FIG. 6. Solution at $4 \mathrm{~h}$ for CNTRL along the same vertical cross section of Fig. 5. Panels compare the first three terms on the right-hand side of the prognostic pressure equation [Eq. (1)]: (a) term I: $\bar{\rho} g w$, contoured at $10 \mathrm{~Pa} \mathrm{~s}^{-1}$ intervals; (b) term II: $-\mathbf{V} \cdot \nabla p^{\prime}$, contoured at $0.2 \mathrm{~Pa} \mathrm{~s}^{-1}$ intervals; (c) term III: $-\rho c_{s}^{2} \boldsymbol{\nabla} \cdot \mathbf{V}$, contoured at $25.0 \mathrm{~Pa} \mathrm{~s}^{-1}$ intervals. Solid (dashed) lines indicate positive (negative) values, with zero lines being omitted.

RESET_W (RESET_UV), all information related to $\partial w / \partial z\left(\nabla_{H} \cdot \mathbf{V}\right)$ is eliminated at restart time, while $\nabla_{H} \cdot \mathbf{V}(\partial w / \partial z)$ remains unchanged. Thus, when RESET_W is restarted, the 3D divergence in region 1 (region 2) is more positive (negative) than it should be. Consequently, from Eq. (1) and as shown in Fig. 8, a negative (positive) pressure perturbation is created in region 1 (region 2) in response to the impulsive loss of velocity information.

Figures 9a,b depict, for experiments CNTRL and RESET_W, respectively, the perturbation pressure $8 \mathrm{~s}$ after restart (i.e., at $t=4: 00: 08)^{3}$ for the same vertical cross section shown in Fig. 5. In agreement with the foregoing discussion, RESET_W (Fig. 9b) shows a pressure field dominated by a vertical low-over-high pattern. The maximum positive (negative) anomalies are located in the region where $\nabla_{H} \cdot \mathbf{V}$ is a minimum (maximum) at $4 \mathrm{~h}$, as shown in Fig. 9c. Because $\partial w / \partial z$ is zero at restart, $\nabla_{H} \cdot \mathbf{V}$ represents the incomplete 3D divergence. Thus, in regions where $\nabla_{H} \cdot \mathbf{V}$ is positive (negative), a negative (positive) pressure perturbation is induced. A similar structure also is found along other cross sections (not shown).

Equivalently, for RESET_UV, in which $\nabla_{H} \cdot \mathbf{V}(\partial w /$ $\partial z$ ) is eliminated (remains unchanged) at $4 \mathrm{~h}$, the $3 \mathrm{D}$ divergence in region 1 (region 2) of Fig. 7 upon restart is more negative (positive) than it should be. Equation (1) indicates that the pressure will respond by generating an artificial high (low) at the top (bottom) of the updraft, as indicated in Fig. 10. The corresponding nu-

\footnotetext{
${ }^{3}$ This time is selected because history files from the withdrawal experiments are saved at 8-s intervals, and thus $t=4: 00: 08$ is the first time for which history data are available following restart. The results shown for this time are representative of $t=4: 00: 04$, which is the first big time step.
}

merical solution (Fig. 11) corroborates this conjecture. Because $\nabla_{H} \cdot \mathbf{V}=0$ at restart, the $3 \mathrm{D}$ divergence is due solely to $\partial w / \partial z$. As expected, the maximum positive (negative) pressure perturbation is located in the region where $\partial w / \partial z$ is a minimum (maximum).

The low-over-high dipole in Figs. 8 and $9 \mathrm{~b}$ suggests that restoration of updrafts in RESET_W is driven by the induced vertical pressure gradient force (PGF). However, concomitantly, the PGF works against the horizontal velocity field, with a positive (negative) pressure perturbation located in the region where the winds converge (diverge). The results from RESET_W (Figs. $5 \mathrm{~d}-\mathrm{f})$ thus indicate that vertical motion is restored by the induced vertical PGF more efficiently than the horizontal velocity field is destroyed by the induced horizontal $P G F$. In contrast with RESET_W, the high-over-low dipole in Figs. 10 and 11b for RESET_UV indicates that the convective updraft is weakened by the induced vertical PGF. On the other hand, the induced PGF tends to favor the regeneration of a horizontal velocity field that is consistent with the dynamic structure of the mature MCS, with a positive (negative) pres-

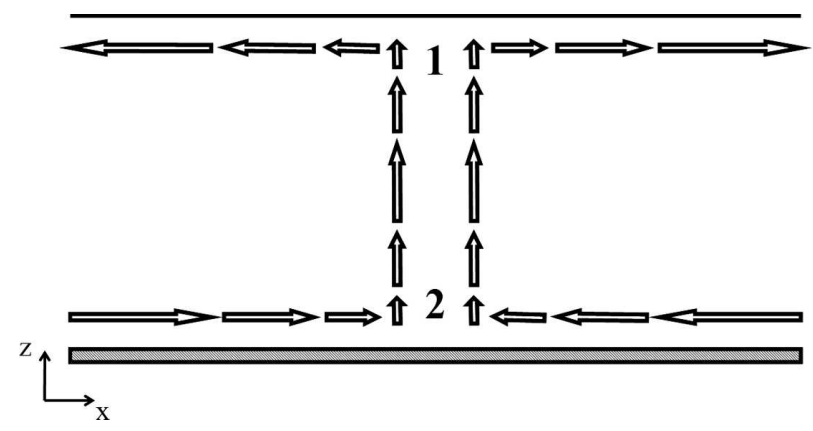

FIG. 7. Idealized convective cell in which the return circulation is weak and distributed over a broad area. 

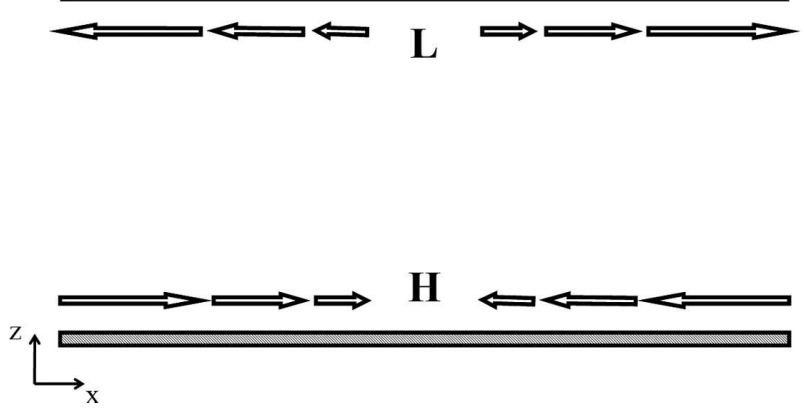

FIG. 8. Idealization of perturbation pressure induced shortly after the elimination of the updraft in Fig. 7. (Proxy for experiment RESET_W.)

sure perturbation located in the region where the wind diverges (converges). The results from RESET_UV (Figs. $5 \mathrm{~g}-\mathrm{i}$ ) suggest that vertical motion is destroyed more efficiently by the induced vertical PGF than the
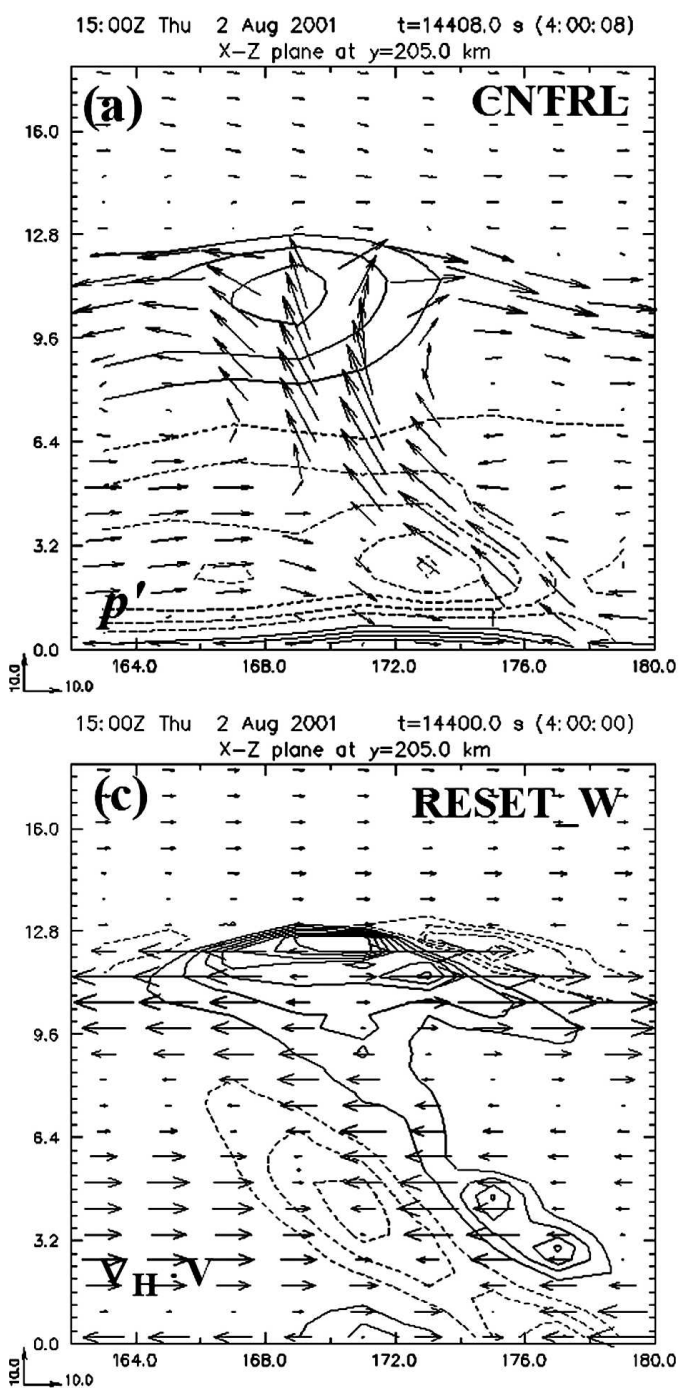

horizontal velocity field is restored by the induced horizontal PGF.

To quantify this behavior, we examine the acceleration associated with the induced PGF shortly after restart in RESET_W and RESET_UV. Figure 12 shows vertical cross sections of the pressure gradient acceleration (PGA) in the zonal, meridional, and vertical directions (XPGA, YPGA, and VPGA, respectively) $8 \mathrm{~s}$ after restart in RESET_W and RESET_UV. The solution from CNTRL also is shown for comparison, and in Fig. 12a, velocity vectors are plotted to illustrate updrafts and downdrafts. Induced PGAs in RESET_W and RESET_UV are at least one order of magnitude stronger than the PGAs in the unperturbed solution from CNTRL (note the difference in contour intervals), with values of perturbation pressure in RESET_W and RESET_UV reaching $1700 \mathrm{~Pa}$ (see, e.g., Figs. 9b and 11b). These extremely strong perturbations are part of

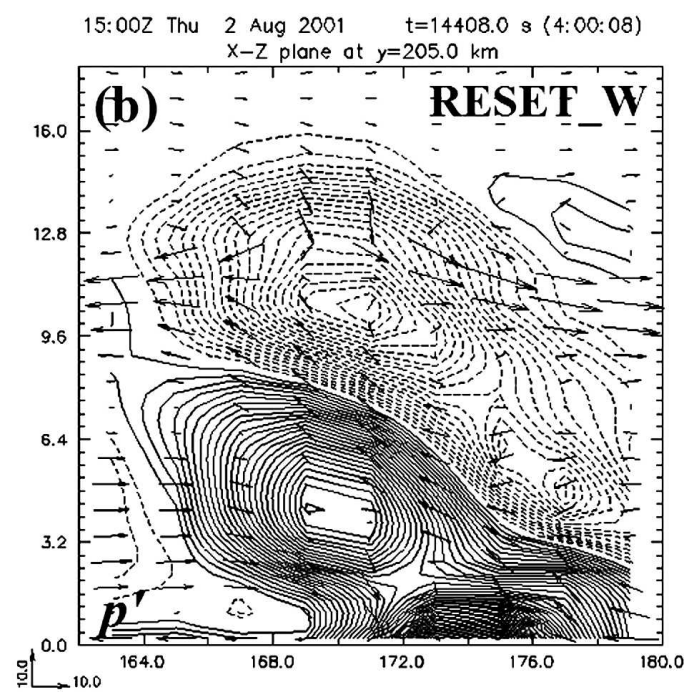

FIG. 9. Vertical cross sections in the same $x-z$ plane as in Fig. 5, but for (a), (b) storm-relative velocity vectors (plotted at every other vertical grid point) and perturbation pressure (contour interval of $50 \mathrm{~Pa}$ ) at $t=8 \mathrm{~s}$ following restart, and (c) horizontal divergence (contour interval of $\left.2 \times 10^{-3} \mathrm{~s}^{-1}\right)$ at $t=4 \mathrm{~h}$. In all panels, solid (dashed) lines indicate positive (negative) values, with zero lines being suppressed. 

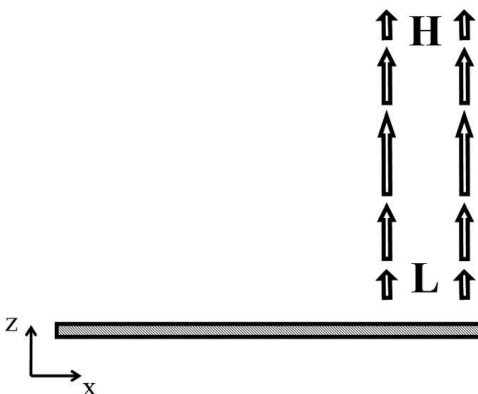

FIG. 10. Idealization of perturbation pressure induced shortly after the elimination of the horizontal motion field in Fig. 7. (Proxy for experiment RESET_UV.)

a "transient response" in the dynamic adjustment process and are quickly damped (see section 6).

As depicted in Fig. 12d (Fig. 12g), the XPGA in RESET_W (RESET_UV) induces horizontal divergence

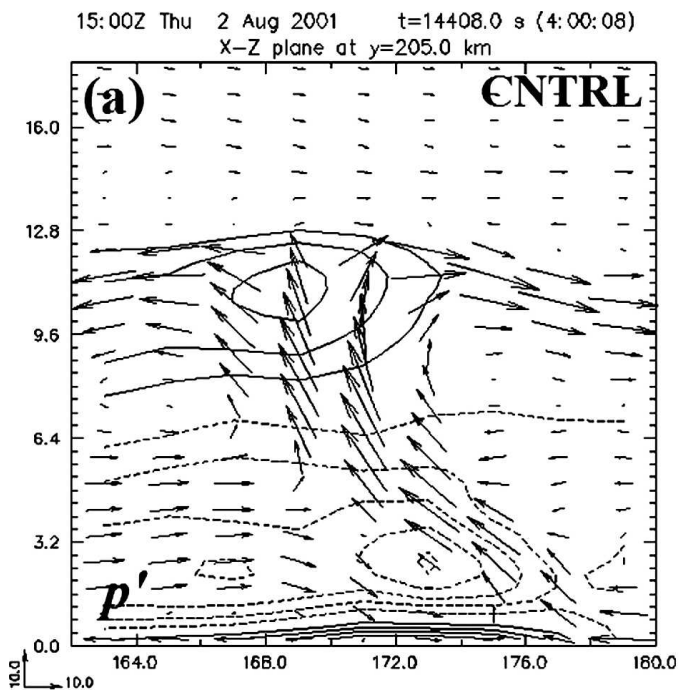

15:00z Thu 2 Aug $2001 \quad t=14400.0 \mathrm{~s}(4: 00: 00)$

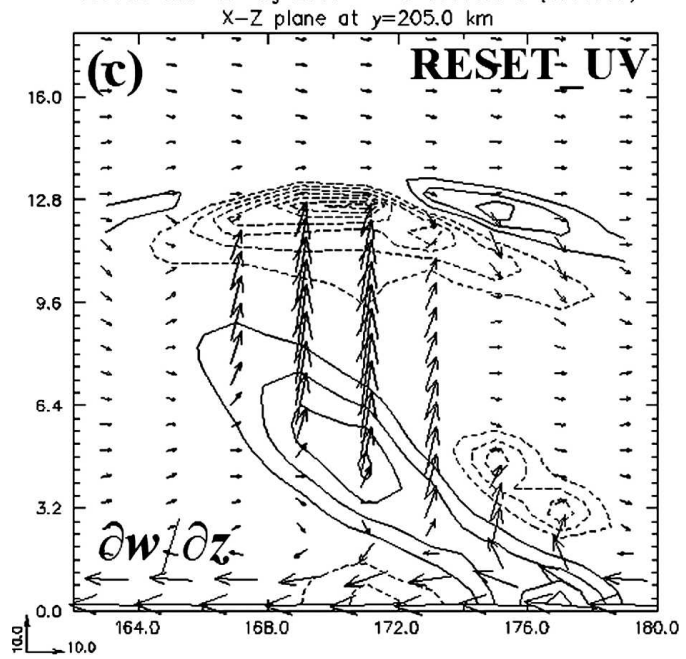

(convergence) in the so-called "midaltitude radial convergence region" $\left(\mathrm{MARC}^{4}\right)$, and along the gust front. The XPGA also induces convergence (divergence) aloft, at anvil level. Thus, the numerical solution indicates that in RESET_W (RESET_UV), the correct horizontal velocity tends to be destroyed (restored) by the induced XPGA. On the other hand, the meridional pressure acceleration, YPGA, is considerably weaker, which is not surprising given that the strongest pressure gradients in all experiments occur in the cross-line direction.

\footnotetext{
${ }^{4}$ The expression midaltitude radial convergence is jargon from radar meteorology referring to a sector in squall lines where the rear-to-front flow encounters the leading updrafts, enhancing convergence locally (Weisman 2001). The numerically simulated MARC is well defined in Fig. 9c by the area dominated by convergence within the region $z=2.0$ to $6.8 \mathrm{~km}$.
}

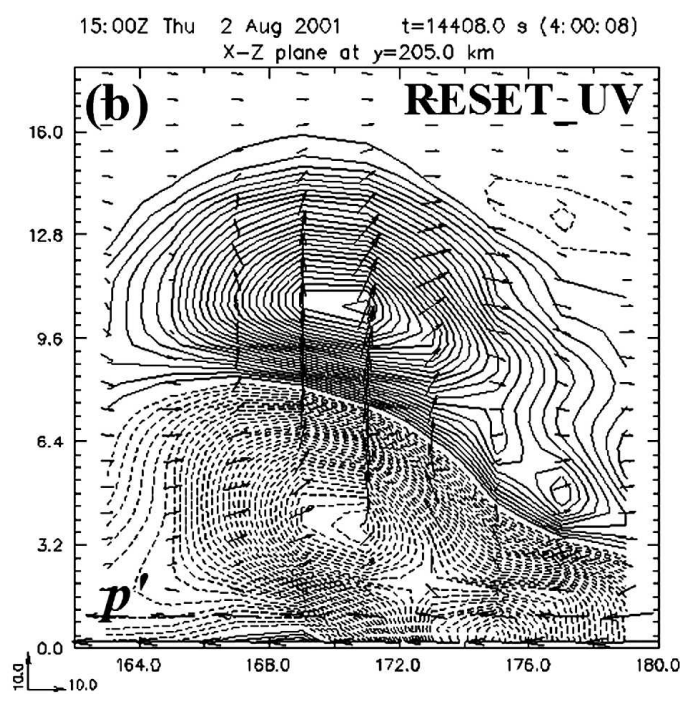

FIG. 11. Same as in Fig. 9, except for RESET_UV and (c) showing the initial vertical divergence $(\partial w / \partial z \times$ $\left.10^{3} \mathrm{~s}^{-1}\right)$ 

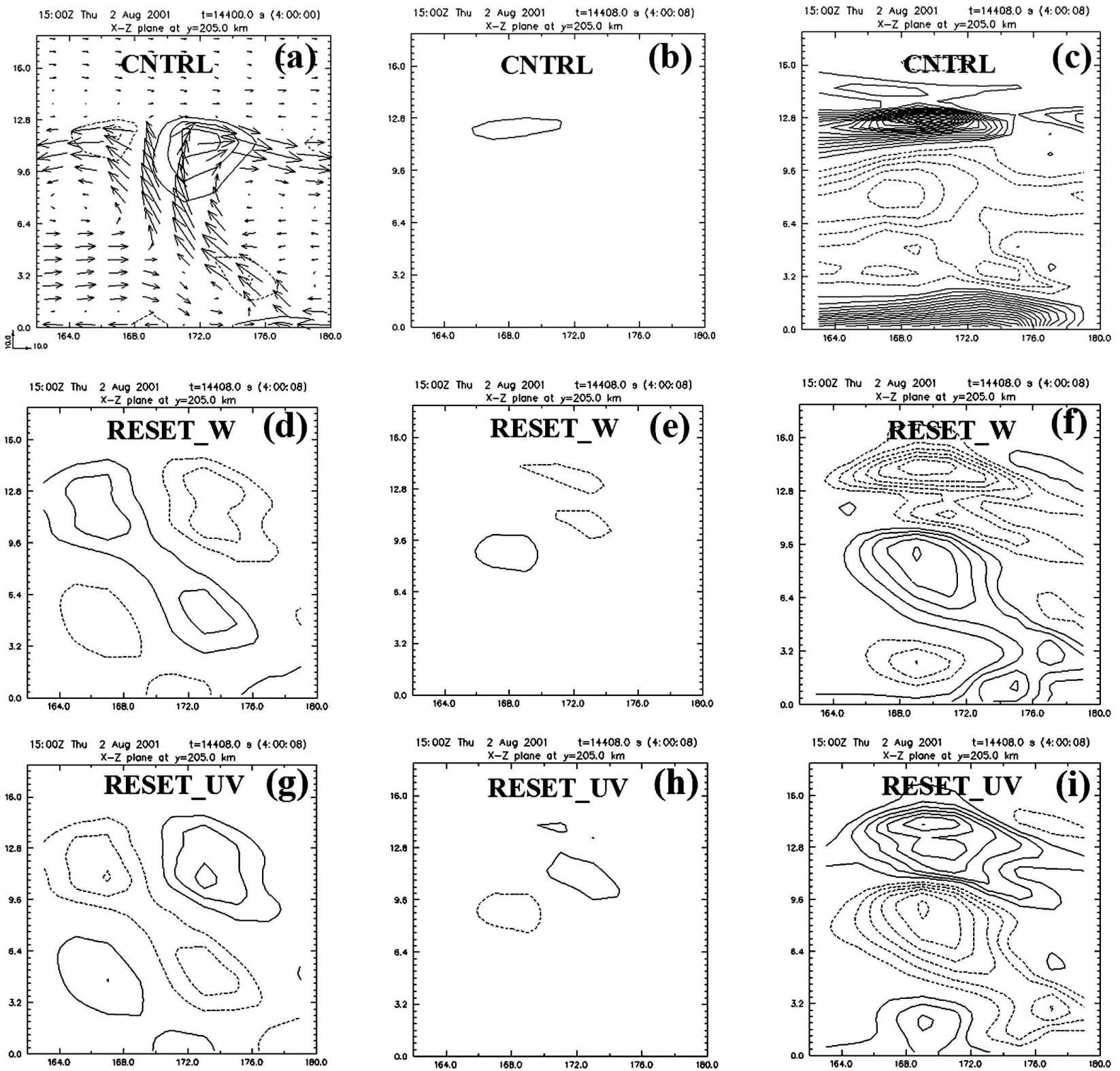

FIG. 12. Vertical cross sections, in the same $x-z$ plane as Fig. 5, of PGA in $\mathrm{m} \mathrm{s}^{-2}$ in the (a), (d), (g) $x$ direction (XPGA); (b), (e), (h) $y$ direction (YPGA); and (c), (f), (i) $z$ direction (VPGA) at $t=8 \mathrm{~s}$ following restart. The contour interval is $0.025 \mathrm{~m} \mathrm{~s}^{-2}$ in (a) $-(\mathrm{c})$, and $0.200 \mathrm{~m} \mathrm{~s}^{-2}$ in (d)-(i). Solid (dashed) lines indicate positive (negative) values, with zero line suppressed. Storm-relative velocity vectors for CNTRL are shown in (a), plotted at every other vertical grid point.

More importantly, both the XPGA and YPGA are small compared to the VPGA, as shown in Fig. 12f for RESET_W and Fig. 12i for RESET_UV. The VPGA, in turn, works toward restoring vertical motion in RESET_W and tends to destroy it in RESET_UV. Note, for RESET_UV (Fig. 12i), the presence of downward (upward) acceleration where updrafts (downdrafts) exist initially. The same is true for different vertical cross sections (not shown).

Regarding the role played by $\bar{\rho} g w$ [Eq. (1)] in the pressure response, we note that when RESET_UV is restarted, this forcing term remains unaltered (because $w$ is not changed), whereas in RESET_W, this term is zero. Hence, if $\bar{\rho} g w$ is to play a primary role in forcing the pressure in our simulations, then a significantly different behavior would be expected at the early stages of these two simulations. However, there is no discernible distinction in the spatial distribution of the pressure field immediately following restart of RESET_W and RESET_UV (Figs. 9b and 11b, respectively), except for 

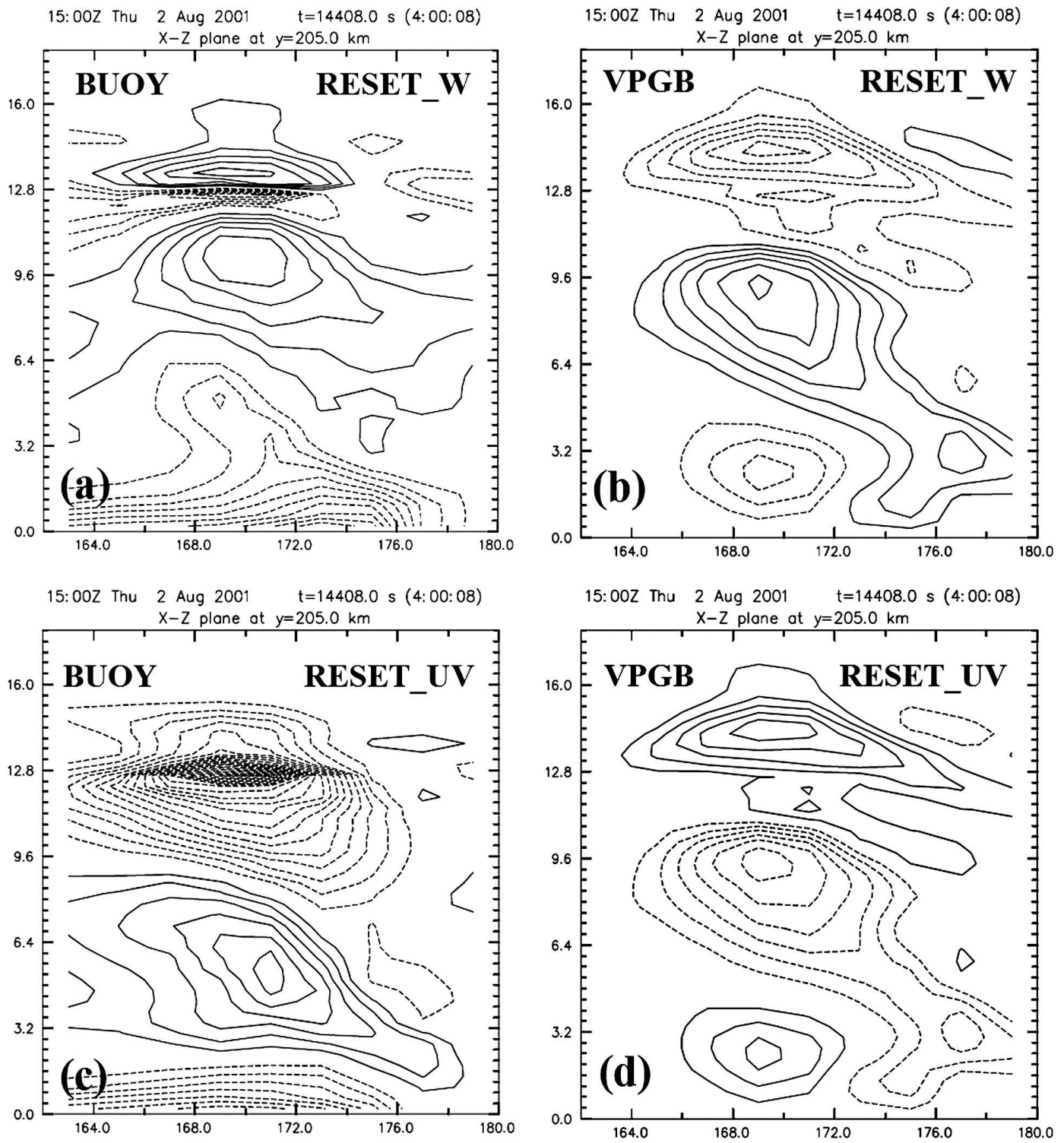

FIG. 13. Vertical cross sections of vertical acceleration due to (a), (c) BUOY and (b), (d) VPGB in m s${ }^{-2}$ at $t=$ $8 \mathrm{~s}$ following restart for (a), (b) RESET_W and (c), (d) RESET_UV. BUOY (VPGB) is contoured at $0.05 \mathrm{~m} \mathrm{~s}^{-2}$ $\left(0.2 \mathrm{~m} \mathrm{~s}^{-2}\right)$ intervals. Solid (dashed) lines indicate positive (negative) values, with zero line being omitted. Domain is the same as in Fig. 5.

the inverted sign, which is induced by the divergence term. Thus, by comparing RESET_W and RESET_UV, it is clear that the $\bar{\rho} g w$ forcing term in the initial condition has no qualitative influence on the solution and only a secondary quantitative influence.

\section{c. Buoyancy effects}

Because buoyancy (BUOY) also is a forcing term in the vertical momentum equation, its potential influence on dynamic adjustment also must be considered. Figure 13 shows the BUOY field alone (left panels), and the combined acceleration due to the vertical pressure gradient and BUOY (VPGB; right panels) across the main bow echo segment $8 \mathrm{~s}$ after restart of experiments RESET_W and RESET_UV, where

$$
\mathrm{BUOY}=g\left(\frac{\theta^{\prime}}{\bar{\theta}}-\frac{p^{\prime}}{\gamma \bar{p}}+\frac{q_{v}^{\prime}}{\varepsilon+\overline{q_{v}}}-\frac{q_{v}^{\prime}+q_{l i}}{1+\overline{q_{v}}}\right)
$$

and

$$
\mathrm{VPGB}=-\frac{1}{\bar{\rho}} \frac{\partial p^{\prime}}{\partial z}+\mathrm{BUOY}
$$


In Eq. (3), $\gamma$ is the ratio of the specific heats at constant pressure and volume, $q_{v}$ is the water vapor mixing ratio, $\varepsilon$ is the ratio of the gas constants for dry air and water vapor $(\varepsilon=0.622)$, and $q_{l i}$ is the total mixing ratio for ice and liquid water species (cloud water, rainwater, cloud ice, snow, and hail). Primes (overbars) refer to perturbation (base state) fields.

Comparing Figs. 12f and 12i with Figs. 13a and 13c, respectively - and noting the different contour intervals-BUOY is one order of magnitude smaller than VPGA induced early in RESET_W and RESET_UV. On the other hand, the full vertical acceleration VPGB (Figs. 13b and 13d) has the same order of magnitude as the corresponding VPGA. Similar results are found in other cross sections along the simulated squall line. This indicates that the contribution of BUOY to the restoration (or destruction) of vertical velocity in our experiments is secondary compared to VPGA.

\section{d. Response of the wind field shortly after restart time}

Figure 14 compares vertical cross sections along the apex of the main bow echo of horizontal $\left(\nabla_{H} \cdot \mathbf{V}\right)$ and vertical $(\partial w / \partial z)$ velocity divergence at $t=4: 00: 08$ for CNTRL, RESET_W, and RESET_UV. These fields are used to assess the early response of the horizontal and vertical velocities, respectively, and are relevant to the adjustment rates of kinematic fields. In RESET_W, $\nabla_{H} \cdot \mathbf{V}$ (Fig. 14c) is weakened by the XPGA (Fig. 12d), while $\partial w / \partial z$ (Fig. 14d) is associated with the vertical motion field restored by the VPGA (Fig. 12f). (As discussed above, buoyancy has only a secondary contribution to the restoration of the vertical velocity field in RESET_W.) Note that $8 \mathrm{~s}$ after restart, $\partial w / \partial z$ in RESET_W already exhibits structure similar to that in CNTRL. The overall restoration of $\partial w / \partial z$ is more efficient than the destruction of $\nabla_{H} \cdot \mathbf{V}$, in agreement with the foregoing discussion.

In RESET_UV, $\nabla_{H} \cdot \mathbf{V}$ (Fig. 14e) is associated with the horizontal velocity component restored by the XPGA (Fig. 12g), while $\partial w / \partial z$ (Fig. 14f) is associated with the vertical motion field destroyed by the VPGA (Fig. 12i). This behavior differs from that in RESET_W in several ways. First, despite being initially the same as in CNTRL, $\partial w / \partial z$ in RESET_UV is much weaker $8 \mathrm{~s}$ after restart (Fig. 14f) than in RESET_W. Furthermore, nowhere is $\nabla_{H} \cdot \mathbf{V}$ (Fig. 14e) restored to its correct value (apart from the MARC region, where the XPGA is comparable in magnitude to the VPGA, and, thus, where the horizontal velocity tends to be more correctly regenerated). Similar results are found for other cross sections along the leading edge of the simulated MCS (not shown), indicating that the overall weakening of $\partial w / \partial z$ is more efficient than the regenera- tion of $\nabla_{H} \cdot \mathbf{V}$, again in agreement with the previous analysis.

\section{e. Discussion}

From an acoustic adjustment perspective (Fiedler 2002), our results indicate that the vertical velocity responds to the horizontal velocity, though the reverse is not true. However, one important element missing from Fiedler's analysis needs to be considered, namely, that different combinations of velocity components may contribute differently to dynamic adjustment. Results from the other experiments in Table 1 validate this conjecture. In RESET_U and RESET_UW, the simulated bow echo (not shown) behaves similarly to that in RESET_UV, that is, with the numerical solution deviating significantly from CNTRL, principally in response to the removal of the zonal velocity component $u$ (which is perpendicular to the simulated MCS in our experiments). Conversely, in RESET_V and RESET_VW, the simulations (not shown) behave more like RESET_W, with a solution that quickly becomes similar to that in CNTRL.

To interpret these results, we first note that most of the horizontal divergence in the MCS - which was shown to induce pressure perturbations crucial for the adjustment process-is due to the cross-line winds associated with the advancing surface cold pool, the MARC, and the anvil-level divergence. In our simulation, the cross-line winds are predominantly zonal. Thus, withdrawal of $v$, or $v$ and $w$ together, at 4 h does not perturb the velocity divergence field as significantly as does the withdrawal of $u$, or $u$ and $w$ together. Second, it may appear that the two-component withdrawal experiments place the flow at a disadvantage vis-à-vis recovery compared to withdrawing a single velocity component. Indeed, obtaining $w$ given complete $u$ and $v$ field requires a trivial integration of the mass continuity equation, whereas obtaining $u$ and $v$ from $w$ alone, in the absence of techniques such as fourdimensional variational data assimilation (4DVAR), requires several assumptions (e.g., potential flow) and suitable boundary conditions. The results presented above clearly indicate, however, that adjustment is driven by velocity divergence and the overall geometry of the convective system. These effects were not addressed in Fiedler's (2002) analysis.

Furthermore, in RESET_W and RESET_UV, the early response of the pressure field follows closely the spatial distribution of the initially inconsistent velocity divergence. We hypothesize that such a response has important implications for dynamic adjustment induced by inconsistent specification of the wind field, as illustrated schematically in Fig. 15. For divergence forcing with a high aspect ratio (Fig. 15a), the expected re- 

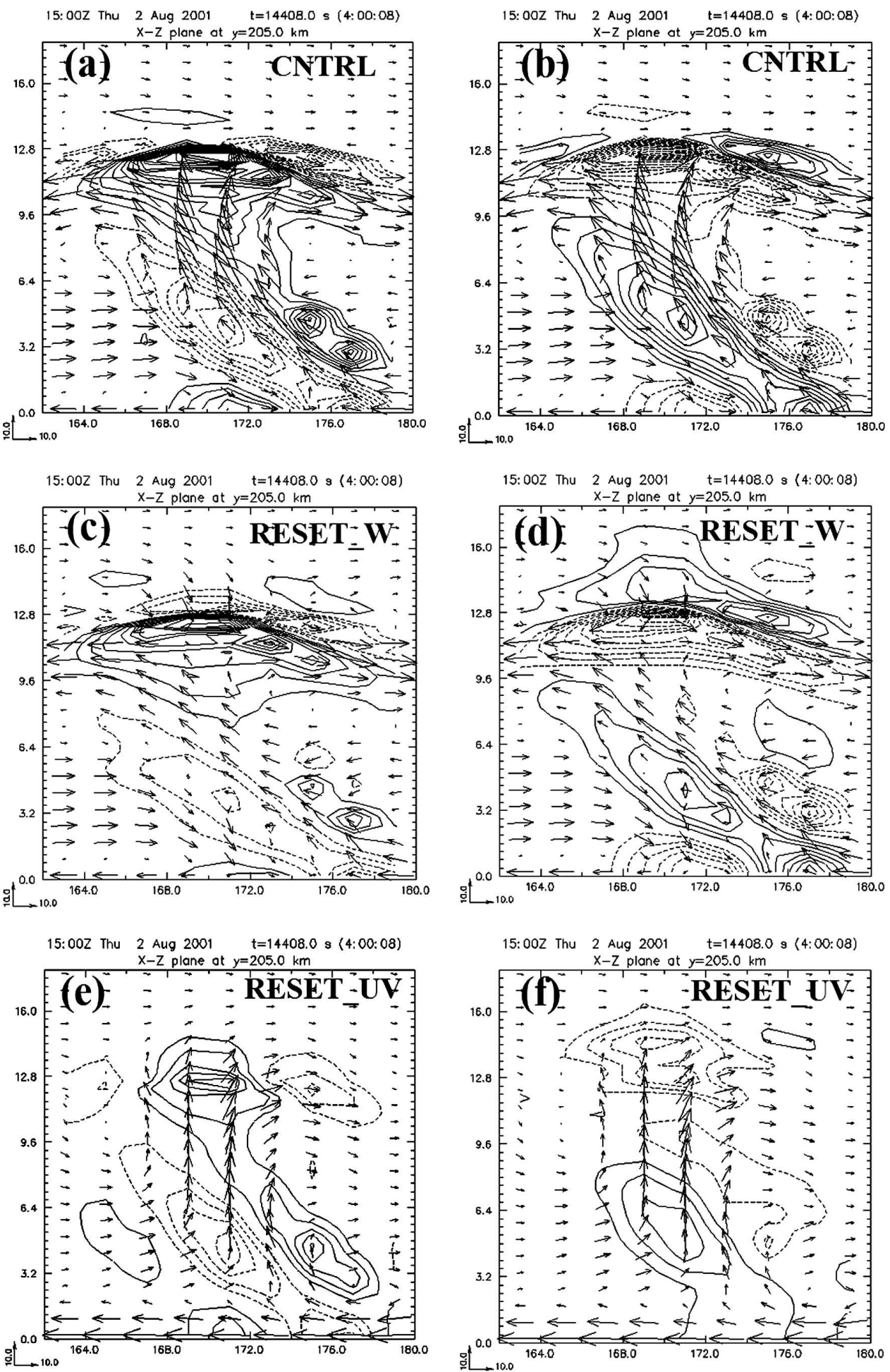

FIG. 14. Vertical cross sections, in the same $x-z$ plane as Fig. 5, of (a), (c), (e) horizontal $\left(\nabla_{H} \cdot \mathbf{V}\right)$ and (b), (d), (f) vertical $(\partial w / \partial z)$ velocity divergence at $t=8 \mathrm{~s}$ following restart. The contour interval is $1 \times$ $10^{-3} \mathrm{~s}^{-1}$. Solid (dashed) lines indicate positive (negative) values, with zero line suppressed. Stormrelative velocity vectors in $\mathrm{m} \mathrm{s}^{-1}$ are plotted at every other vertical grid point. 

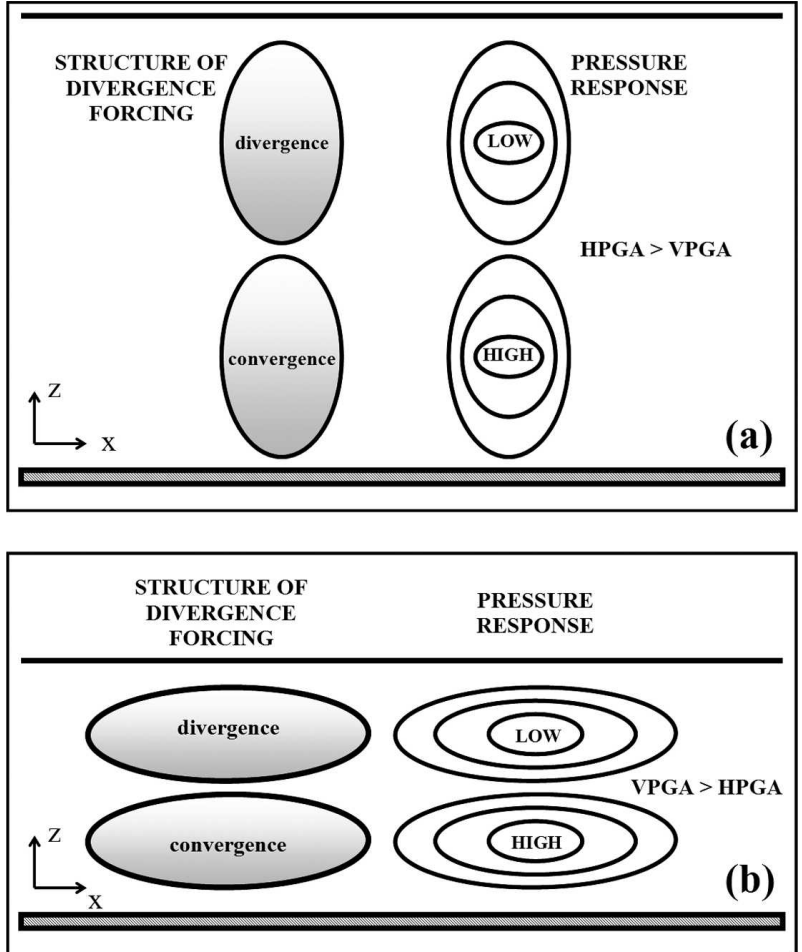

FIG. 15. Schematic in the $x-z$ plane of the pressure response to an imposed divergence field, as governed by the prognostic pressure equation [Eq. (1)]. See the text for details.

sponse is a narrow perturbation pressure field in which the induced horizontal PGA tends to be stronger than the VPGA. Conversely, for divergence forcing having a "pancake" shape (Fig. 15b), the pressure response is more vertically confined, displaying a lower aspect ratio such that the VPGA tends to be strongest.

Our results suggest that this second pattern dominates in both RESET_W and RESET_UV. In this context, it is interesting to note that the upshear-tilted region of vertical motion (e.g., Fig. 5) has an effectively large horizontal extent. Consequently, the divergence patterns, and the corresponding pressure response, have a predominantly horizontal orientation, as shown, for example, in Figs. 9 and 11, and in several other cross sections along the squall line (not shown). The orientation of divergence and convergence patterns, influenced by vertical wind shear, may represent a crucial aspect in determining the effective aspect ratio of a convective system from a dynamic adjustment standpoint. Future studies will be needed to address this issue.

\section{Behavior of acoustic waves}

\section{a. Structure and propagation}

As described by Fiedler (2002), high-frequency acoustic waves are triggered when a perturbation inserted in the velocity field of a nonhydrostatic fully com- pressible model violates mass continuity. Figures 16 and 17 depict, for RESET_W and RESET_UV, respectively, the time evolution at 1-min intervals of the perturbation pressure difference field relative to CNTRL, that is, $p^{\prime}($ RESET_W $)-p^{\prime}(\mathrm{CNTRL})$ in Fig. 16, and $p^{\prime}($ RESET_UV $)-p^{\prime}($ CNTRL $)$ in Fig. 17 at $z=200 \mathrm{~m}$ during the first $9 \mathrm{~min}$ following restart. The most striking feature is a region of intense perturbation pressure, the leading edge of which (indicated by small arrows in Figs. $16 \mathrm{a}-\mathrm{c}$ and $17 \mathrm{a}-\mathrm{c}$ ) propagates outward at approximately the speed of sound $\left(\sim 300 \mathrm{~m} \mathrm{~s}^{-1}\right)$. This pressure "front" does not represent a true shock wave, though, which would be accompanied by significant changes in entropy and velocity ${ }^{5}$ (e.g., Liepman and Roshko 1957; Lighthill 1978). A comparison of Figs. 16 and 17 highlights pressure anomalies of opposite sign that are consistent with the difference in the sign of the original pressure dipole created by the reset (Figs. 9b and 11b), thus representing a linear response to the initial perturbation. In RESET_W (Fig. 16), the perturbation pressure difference gradually weakens, indicating that the solution converges to that of CNTRL. Conversely, in RESET_UV (Fig. 17), significant pressure differences persist in the center of the domain (where the storm system is positioned; Figs. 17g-i), representing the strong deviation between solutions from CNTRL and RESET_UV.

Figure 18 shows the oscillatory behavior at distinct vertical levels of the pressure fluctuations at a fixed point near the center of the domain $(x=144 \mathrm{~km}, y=$ $204 \mathrm{~km}$ ) during the first 5-min after restart in RESET_W and RESET_UV. Higher-frequency oscillations, well above the acoustic cutoff frequency (of $0.015 \mathrm{~s}^{-1}$ ), are present in the first $1 \mathrm{~min}$ of both simulations, with the pressure fluctuation at $z=5 \mathrm{~km}$ being out of phase with respect to waves at lower levels, suggesting the presence of vertically propagating sound waves. After 1 min, a distinct regime is established in which the phase of the waves becomes vertically aligned and the amplitude of the pressure perturbations decays with height. This regime shares several characteristics of Lamb waves, suggesting that the early stages of the adjustment are dominated by high-frequency vertically propagating sound waves followed by an oscillatory regime where Lamb waves dominate.

\section{b. Numerical representation}

The central role of acoustic waves in the dynamic adjustment process makes their numerical representa-

\footnotetext{
${ }^{5}$ Shock wave refers to strong shock waves. Weak shock waves also are possible, for which the propagation speed is nearly equal to the speed of sound and variations of entropy and velocity across the wave front are very small.
} 

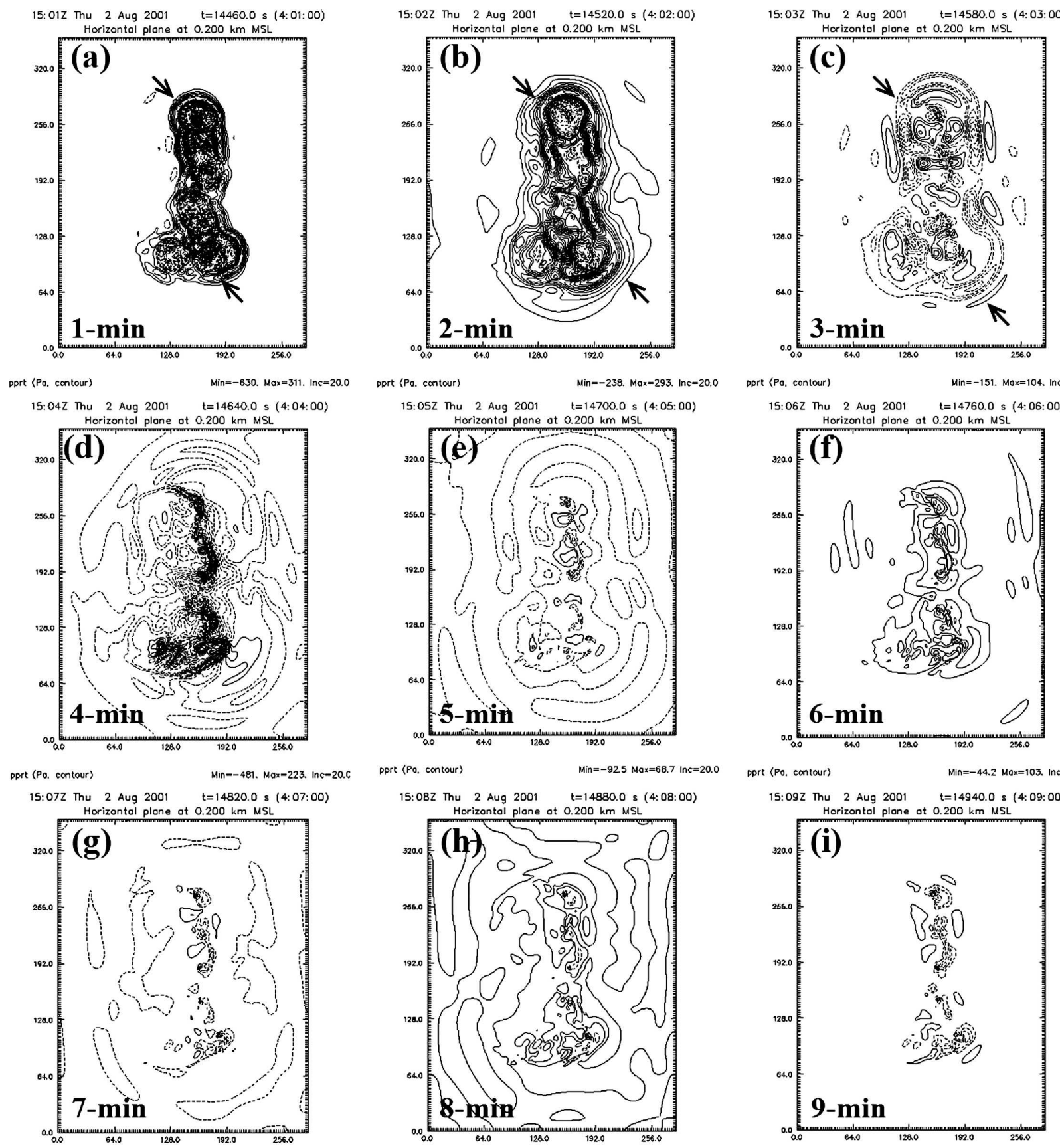
Ppre (Po, contour)
Min $=-151$. Mox $=104 . \ln \mathrm{c}=20.0$
15: 062 Thu 2 Aug $2001 \quad t=14760.0 \mathrm{~s}$ (4:06:00)
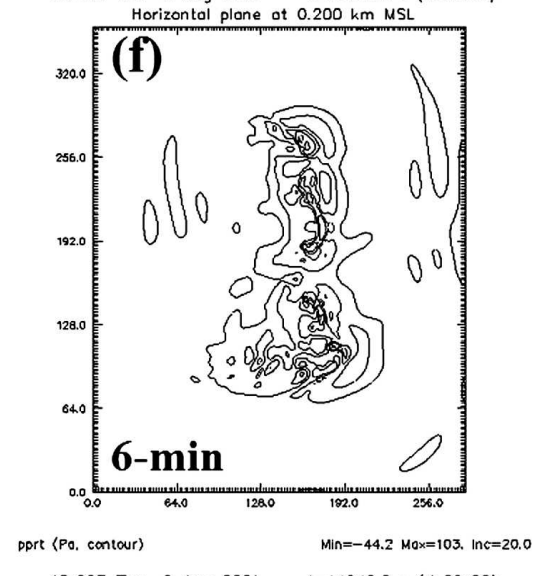

Min $=-44.2$ Mox $=103 . \ln c=200$
15: 092 Thu 2 Aug $2001 \quad t=14940.0$ s $(4: 09: 00)$

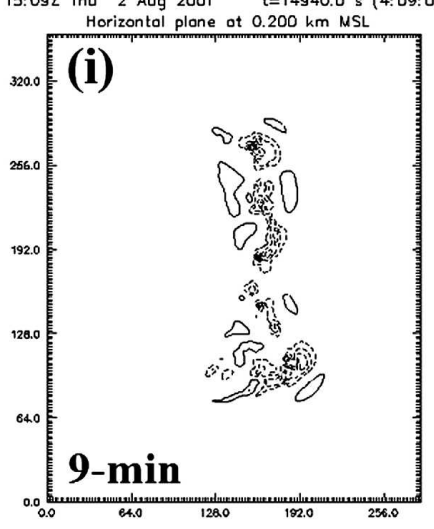

$\operatorname{Dprt}$ (Po, contour) Min=-124. Max=40.7 Inc=20.6

pprt (Po. contor)

Min--89.5 Max-73.5 Inc-20.0

Min= $=-131$. Max $=41.9$ in $c=20.0$

FIG. 16. Early evolution of the perturbation pressure difference field (20-Pa contour interval) between RESET_W and CNTRL, i.e., $p^{\prime}\left(R_{E S E T}+\mathrm{W}\right)-p^{\prime}(\mathrm{CNTRL})$, at $z=200 \mathrm{~m}$ every minute for the first $9 \mathrm{~min}$ following restart. Solid (dashed) lines indicate positive (negative) values, with zero lines suppressed. The entire horizontal domain is shown. (a)-(c) Arrows indicate the front of the main pressure disturbance advancing away from the center of the domain at approximately the speed of sound. The pressure difference field at later stages [especially seen in (g)-(i)] provides indication of how much the simulation deviates from CNTRL after the dispersion/ damping of high-amplitude acoustic modes.

tion especially relevant. Because of their large phase speeds, acoustic waves are not physically important in cloud-scale processes (some tornadoes may be an exception). It is for this reason that cloud-scale models [e.g., ARPS, the fifth-generation Pennsylvania State University-National Center for Atmospheric Research Mesoscale Model (MM5), the Colorado State University Regional Atmospheric Modeling System 

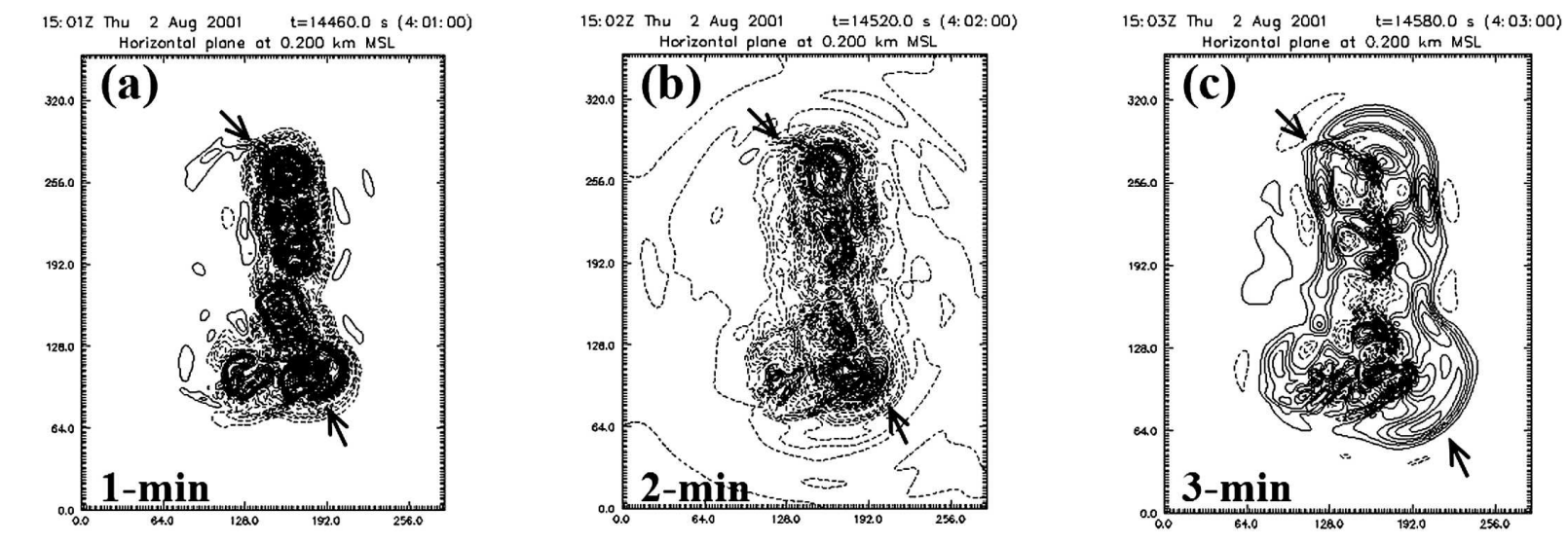

pprt 〈Po. contour) Min=-338. Max $=707$. Inc $=20.0$

Ppre $(P \mathrm{~Pa}$, contour $)$

Min $=-339$. Max $=372$. Inc $=20.6$
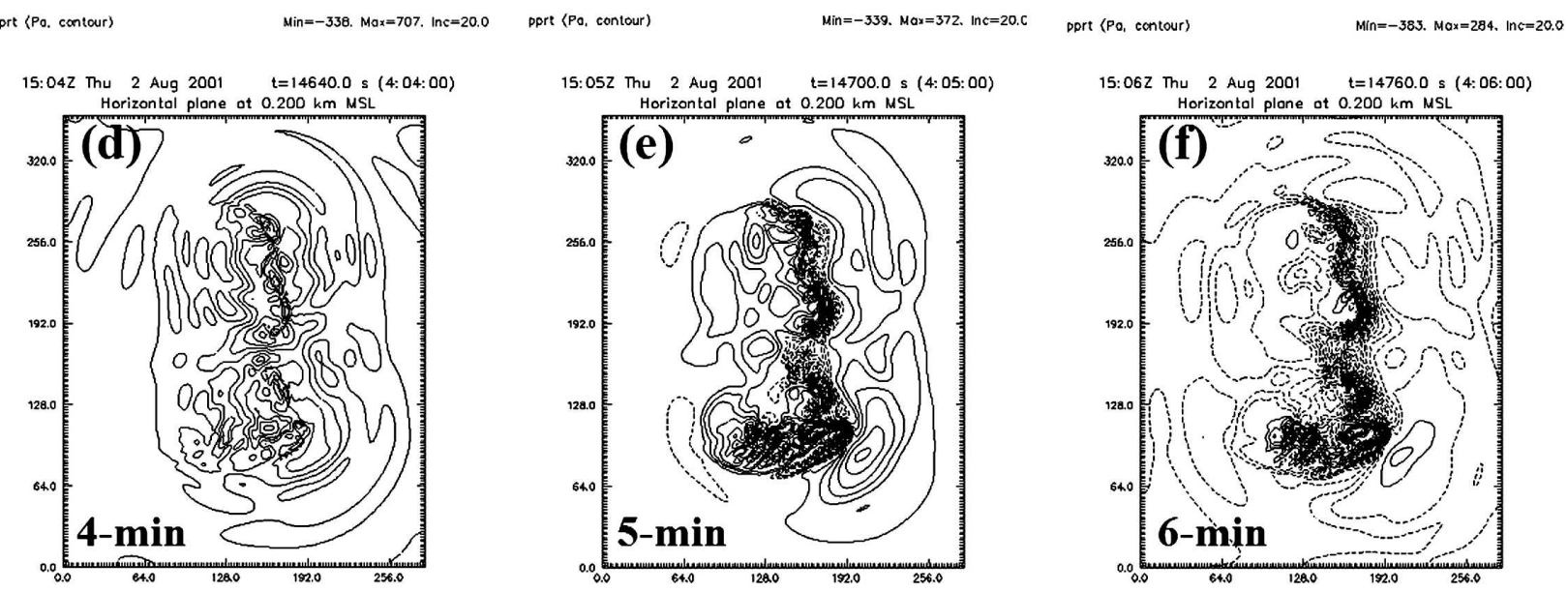

part $\langle$ Po, contour) Min $=-47.1$ Max $=147, \ln =20 . \mathrm{C}$

DPrt (Po. contour)

Min--454. Max-327. Inc-20.C
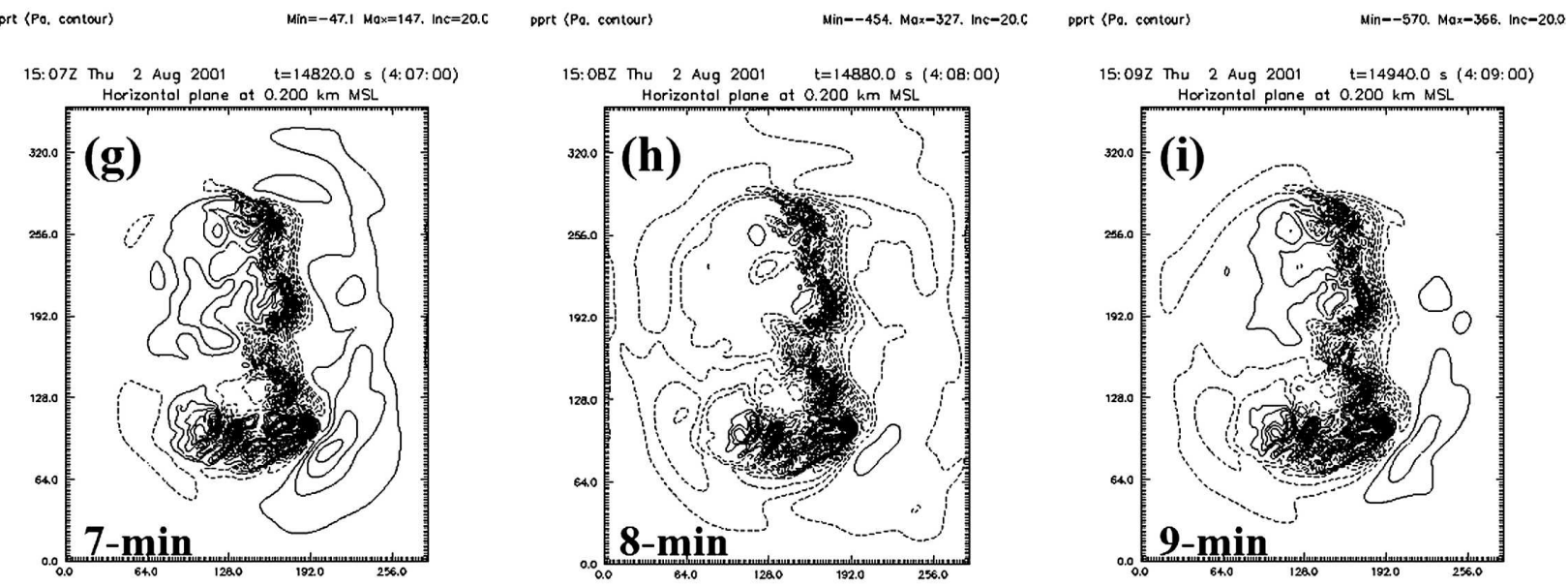

ppre (Po, contour)

Min $=-553$. Max $=459$. In $c=20 . C$ pprt $\langle$ Po, contour $\rangle$

Min--634. Mox=452. In 8 -20.1 ppre (Po, contour)

Min $=-626$. Max $=476 . \ln C=20.0$

FIG. 17. Same as in Fig. 16, but for RESET_UV.

(CSU-RAMS), and the Weather Research and Forecasting Model (WRF)] treat acoustic modes in an approximate manner, reaping the benefits of a fully compressible, hyperbolic system of equations though without the severe time step constraint associated with linear stability. The approximations include a mode-splitting time integration technique, like the one employed in our simu- lations, which contains a weak instability that is effectively controlled by divergence damping (Skamarock and Klemp 1992, 1994; Durran 1999). The solution otherwise is accurate, although waves near the grid scale always have the largest phase and amplitude errors. As noted below, divergence damping affects only the amplitude of the acoustic waves and not their phase speed. 

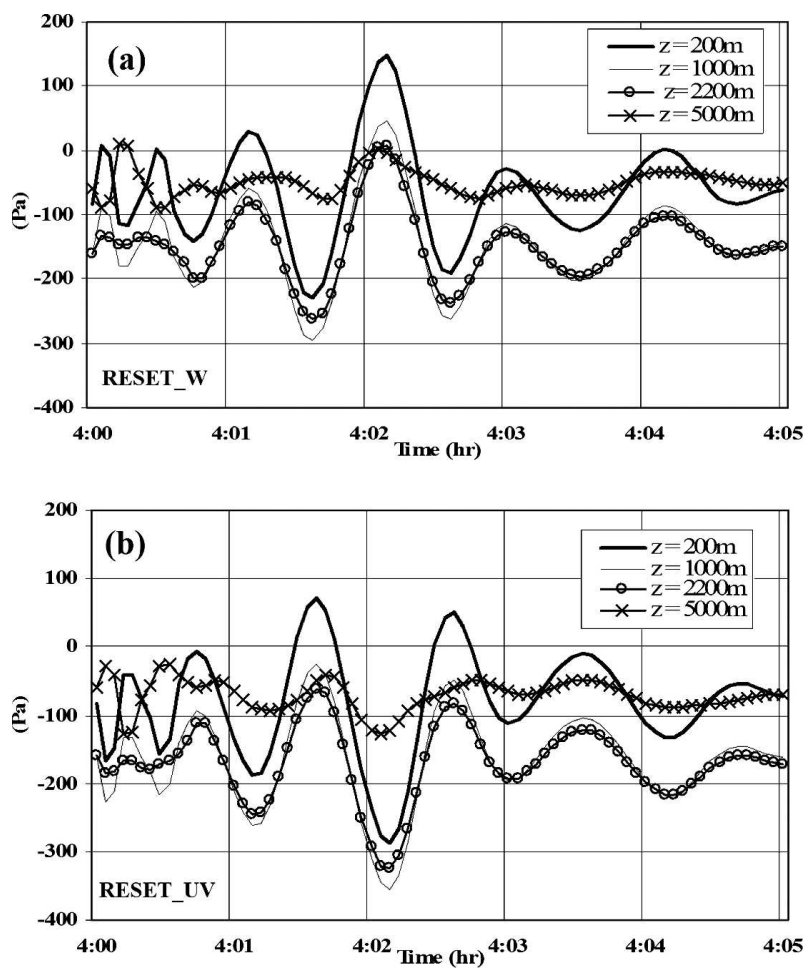

FIG. 18. Time series for the first 5 min after restart $(t=4 \mathrm{~h})$ of perturbation pressure $(\mathrm{Pa})$ at grid point $(x, y)=(140,204) \mathrm{km}$ for (a) RESET_W and (b) RESET_UV at four vertical levels. Data are plotted every $8 \mathrm{~s}$.

Another approximation is the use of an implicit numerical scheme for the vertical momentum and pressure equations. This does in fact reduce the vertical propagation of short wavelength acoustic waves but still avoids coupling with vertically propagating internal gravity waves (e.g., Durran 1999). It also removes the constraint on the small time step size associated with the typically much smaller vertical than horizontal grid interval, especially at low levels. Finally, radiation lateral boundary conditions, like those employed here, allow internal gravity waves, but not acoustic waves, to propagate out of the domain with minimum reflection. This provides another justification for divergence damping.

Either individually or taken together, these considerations might suggest that acoustic adjustment is improperly handled in our simulations. However, none of the approximations described above greatly impacts the phase speed of acoustic waves, which, as shown by Droegemeier and Davies-Jones (1987), would lead to artificially strong coupling with internal gravity waves and thus a deleterious impact on acoustic adjustment. To confirm this notion in the context of divergence damping, we performed additional simulations (results not shown) in which divergence damping was switched off. Although acoustic wave amplitude decreased more slowly with time, dynamic adjustment was not impacted, and the results were essentially identical to those in which divergence damping was included.

\section{c. Relation to hydrostatic adjustment}

The adjustment mechanism described herein shares with hydrostatic adjustment (HA; Bannon 1995) the property that high-amplitude acoustic waves are responsible for relatively rapid (on the order of a few minutes) changes among certain variables. However, an important contrast is that in our experiments, adjustment is induced not by the prescription of an unbalanced heat source but rather by kinematic imbalances.

For example, the pressure and density fields at restart in all experiments are consistent with the presence of a midlevel buoyancy source associated with latent heating. Furthermore, it would be difficult to explain, through HA considerations alone, the early response in perturbation pressure in RESET_W and RESET_UV, which consists of vertical dipoles with distinct signs despite the midlevel buoyancy source in both runs having exactly the same magnitude and sign at the initial time. However, once the pressure perturbations in our experiments have formed shortly after restart-representing a severe departure from hydrostatic balance-their subsequent evolution is at least partially governed by HA.

\section{Summary, conclusions, and ongoing research}

We investigated mechanisms governing the mutual adjustment of mass and velocity fields within an idealized bow echo mesoscale convective system (MCS). Using a 6-h numerical simulation as the control (CNTRL), three-dimensional fields containing incomplete information about the kinematic structure of the MCS at $t=$ $4 \mathrm{~h}$ were generated by resetting the horizontal (experiment RESET_UV) and vertical (experiment RESET_W) velocity components, or combinations thereof, throughout the model domain to their original undisturbed base state. These fields then were used to restart the numerical simulations at $4 \mathrm{~h}$, with the subsequent 2-h integration compared to that of CNTRL.

Our principal findings can be summarized as follows:

- The morphology of the simulated MCS was modified substantially after withdrawing perturbation horizontal velocities, while eliminating the vertical velocity had virtually no impact. This behavior results from the fact that information contained in the horizontal velocity divergence is crucial for forcing the correct vertical motion.

- Incomplete specification of 3D velocity divergence 
induced an artificially strong vertical pressure gradient acceleration that destroyed (restored) updrafts and downdrafts in the absence of information about the horizontal (vertical) velocity.

- Because strong horizontal divergence in squall lines/ bow echoes is produced principally by cross-line winds (forward-propagating surface outflow, frontto-rear and rear-to-front flows, and anvil-level flows), our results show that these velocity components control dynamic adjustment and thus should be well initialized in storm-scale models, at least in the case of linear convection.

- High-frequency acoustic waves of large amplitude were triggered in all experiments, characterizing a "transient evolution" in dynamic adjustment consistent with linear theory (Fiedler 2002). This linear response consisted of oscillations sharing characteristics of vertically propagating sound waves in the first 1 min and of Lamb waves thereafter.

- The induced dynamic adjustment had a relatively short time scale (less than $10 \mathrm{~min}$ ) owing to the speed of acoustic waves, and it was shown that this adjustment period is not influenced by the presence of divergence damping in the momentum equations.

- In the context of Fiedler's (2002) work, the simulated bow echo displayed an effective low aspect ratio, though our results suggest that such an interpretation might not be universally applicable.

Although caution must be exercised when generalizing results from such a limited set of experiments, we believe that, in the context of storm-scale model initialization (under the assumption that all other fields are well characterized), knowledge of the horizontal velocity (or stated another way, the horizontal divergence) is more important than knowledge of the vertical velocity, and thus the former should be measured as accurately and completely as possible. This finding is important because it addresses, qualitatively, the first question posed in the introduction: "Which variables are most important for explicitly predicting the evolution of an existing convective system?" Furthermore, as indicated by Weygandt et al. (1999), this result is encouraging because, among the meteorological variables retrieved from single-Doppler radar data, the horizontal velocity is one of the most accurate (e.g., Gao et al. 2001; Weygandt et al. 2002b).

Our results also suggest that, despite its importance in characterizing the inner structure of a convective system (Fritsch and Forbes 2001), the pressure field contains highly redundant information compared to the three-dimensional velocity field. This result is relevant to the second question posed in the introduction: "To what extent do variables at the storm-scale contain redundant information?" We showed that specification of the correct three-dimensional velocity divergence induces the correct pressure (mass) field provided that the correct thermal field is adequately specified (which, in data assimilation, is of course related to both pressure and wind). In fact, the withdrawal of the pressure perturbation field alone has virtually no impact on our simulation, as will be discussed in a subsequent paper.

Experiments similar to those described here, but for other modes of convection (e.g., supercells and multicells), suggest extensibility of the current results, though with some exceptions. That work will be reported in subsequent papers. The role of vertical environmental shear in lowering the effective aspect ratio of convective structures-by favoring horizontally oriented divergence patterns-was discussed herein although no definite conclusion can be drawn before examining a wider range of vertical wind profiles.

Additional work addressing dynamic adjustment in deep convective storms is underway and includes the following:

- other modes of convection;

- withdrawal of storm-induced temperature and moisture fields and microphysical variables, in various combinations with one another and with the wind field;

- withdrawal of various fields at different stages of storm evolution;

- a thorough analysis using forecast initialized with real data (Weygandt et al. 2002b; Xue et al. 2003);

- withdrawal of entire storm features, rather than just selected variables.

An analysis based upon storm energetics could lend additional insight into dynamic adjustment at small scales, particularly within sheared flows, whereby a larger portion of the momentum field within the storm (perturbation kinetic energy) is projected into the horizontal. It then may be possible to quantify aspect ratio impacts namely the ratio between vertical and horizontal kinetic energy (E. Kalnay 2002, personal communication).

Acknowledgments. This work represents a portion of Dr. Nascimento's doctoral dissertation in the School of Meteorology at the University of Oklahoma. We are grateful for many useful discussions with Drs. Ming Xue, Eugenia Kalnay, Frederick H. Carr, Brian Fiedler, Alan Shapiro, and David Stensrud and also wish to thank three anonymous reviewers for their constructive comments that greatly improved the quality of the manuscript. Dr. Nascimento was supported in part by 
Brazil's Conselho Nacional de Desenvolvimento Científico e Tecnológico (National Council for Scientific and Technological Development; CNPq) under Grant GDE-201686/90-2. Additional funding for both Dr. Droegemeier and Dr. Nascimento was provided by the National Science Foundation under Grant ATM9981130.

\section{REFERENCES}

Bannon, P. R., 1995: Hydrostatic adjustment: Lamb's problem. $J$. Atmos. Sci., 52, 2302-2312.

Blumen, W., 1972: Geostrophic adjustment. Rev. Geophys. Space Phys., 10, 485-528.

Bretherton, C. S., and P. K. Smolarkiewicz, 1989: Gravity waves, compensating subsidence, and detrainment around cumulus clouds. J. Atmos. Sci., 46, 740-759.

Brewster, K., 2003a: Phase-correcting data assimilation and application to storm-scale numerical weather prediction. Part I: Method description and simulation testing. Mon. Wea. Rev., 131, 480-492.

_ 2003b: Phase-correcting data assimilation and application to storm-scale numerical weather prediction. Part II: Application to a severe storm outbreak. Mon. Wea. Rev., 131, 493507.

Chagnon, J. M., and P. R. Bannon, 2001: Hydrostatic and geostrophic adjustment in a compressible atmosphere: Initial response and final equilibrium to an instantaneous localized heating. J. Atmos. Sci., 58, 3776-3792.

Charney, J., M. Halem, and R. Jastrow, 1969: Use of incomplete historical data to infer the present state of the atmosphere. $J$. Atmos. Sci., 26, 1160-1163.

Crook, N. A., 1996: Sensitivity of moist convection forced by boundary layer processes to low-level thermodynamic fields. Mon. Wea. Rev., 124, 1767-1785.

—_, and J. D. Tuttle, 1994: Numerical simulations initialized with radar-derived winds. Part II: Forecasts of three gust-front cases. Mon. Wea. Rev., 122, 1204-1217.

—_, and J. Sun, 2002: Assimilating radar, surface, and profiler data for the Sydney 2000 forecast demonstration project. $J$. Atmos. Oceanic Technol., 19, 888-898.

— , and _ 2004: Analysis and forecasting of the low-level wind during the Sydney 2000 forecast demonstration project. Wea. Forecasting, 19, 151-167.

Daley, R., 1991: Atmospheric Data Analysis. Cambridge University Press, $457 \mathrm{pp}$.

Davies-Jones, R., R. J. Trapp, and H. B. Bluestein, 2001: Tornadoes and tornadic storms. Severe Convective Storms, Meteor. Monogr., No. 50, Amer. Meteor. Soc., 167-221.

Davis, C. A., and M. L. Weisman, 1994: Balanced dynamics of mesoscale vortices produced in simulated convective systems. J. Atmos. Sci., 51, 2005-2030.

Dowell, D. C., F. Zhang, L. J. Wicker, C. Snyder, and N. A. Crook, 2004: Wind and temperature retrievals in the 17 May 1981 Arcadia, Oklahoma, supercell: Ensemble Kalman filter experiments. Mon. Wea. Rev., 132, 1982-2005.

Droegemeier, K. K., and R. P. Davies-Jones, 1987: Simulation of thunderstorm microbursts with a supercompressible numerical model. Proc. Fifth Int. Conf. on Numerical Methods in Laminar and Turbulent Flow, Montreal, QC, Canada, Concordia University and Cosponsors, 1386-1397.

_, and J. Levit, 1993: Sensitivity of storm-scale predictions to initialization with simulated Doppler radar data. Preprints, 17th Conf. on Severe Local Storms, St. Louis, MO, Amer. Meteor. Soc., 431-435.

Ducrocq, V., J.-P. Lafore, J.-L. Redelsperger, and F. Orain, 2000: Initialization of a fine-scale model for convective-system prediction: A case study. Quart. J. Roy. Meteor. Soc., 126, 30413065.

Duffy, D. G., 2003: Hydrostatic adjustment in nonisothermal atmospheres. J. Atmos. Sci., 60, 339-353.

Durran, D. R., 1999: Numerical Methods for Wave Equations in Geophysical Fluid Dynamics. Springer-Verlag, 465 pp.

Elmore, K. L., D. J. Stensrud, and K. C. Crawford, 2002: Ensemble cloud model applications to forecasting thunderstorms. J. Appl. Meteor., 41, 363-381.

Fiedler, B. H., 2002: A wind transformation for acoustic adjustment in compressible models. Mon. Wea. Rev., 130, 741-746.

Fovell, R. G., 2002: Upstream influence of numerically simulated squall-line storms. Quart. J. Roy. Meteor. Soc., 128, 893-912.

Fritsch, J. M., and G. S. Forbes, 2001: Mesoscale convective systems. Severe Convective Storms, Meteor. Monogr., No. 50, Amer. Meteor. Soc., 323-357.

Gao, J., M. Xue, A. Shapiro, Q. Xu, and K. K. Droegemeier, 2001: Three-dimensional simple adjoint velocity retrievals from single-Doppler radar. J. Atmos. Oceanic Technol., 18, 26-38.

Gilmore, M. S., and L. J. Wicker, 1998: The influence of midtropospheric dryness on supercell morphology and evolution. Mon. Wea. Rev., 126, 943-958.

Houze, R. A., Jr., 1993: Cloud Dynamics. Academic Press, 573 pp.

Johns, R. H., 1993: Meteorological conditions associated with bow echo development in convective storms. Wea. Forecasting, 8 , 294-299.

Kalnay, E., 2003: Atmospheric Modeling, Data Assimilation, and Predictability. Cambridge University Press, $512 \mathrm{pp}$.

Klemp, J. B., and R. B. Wilhelmson, 1978: The simulation of three-dimensional convective storm dynamics. J. Atmos. Sci., 35, 1070-1096.

_ and D. R. Durran, 1983: An upper boundary condition permitting internal gravity wave radiation in numerical mesoscale models. Mon. Wea. Rev., 111, 430-444.

Lamb, H., 1908: On the theory of waves propagated vertically in the atmosphere. Proc. London Math. Soc., 7, 122-141.

_ 1932: Hydrodynamics. Dover Publications, 738 pp.

Laroche, S., and I. Zawadzki, 1994: A variational analysis method for the retrieval of three-dimensional wind field from singleDoppler radar data. J. Atmos. Sci., 51, 2664-2682.

Lazarus, S., A. Shapiro, and K. K. Droegemeier, 2001: Application of the Zhang-Gal-Chen single-Doppler velocity retrieval to a deep convective storm. J. Atmos. Sci., 58, 998-1016.

Li, Q., R. L. Bras, and S. Islam, 1995: Growth and decay of error in a numerical cloud model due to small initial perturbations and parameter changes. J. Appl. Meteor., 34, 1622-1632.

Liepman, H. W., and A. Roshko, 1957: Elements of Gasdynamics. John Wiley and Sons, 439 pp.

Lighthill, J., 1978: Waves in Fluids. Cambridge University Press, $504 \mathrm{pp}$.

Lin, Y. H., R. D. Farley, and H. D. Orville, 1983: Bulk parameterization of the snow field in a cloud model. J. Climate Appl. Meteor., 22, 1065-1092.

Mapes, B. E., 1993: Gregarious tropical convection. J. Atmos. Sci., 50, 2026-2037.

McCaul, E. W., and C. Cohen, 2002: The impact on simulated storm structure and intensity of variations in the mixed layer and moist layer depths. Mon. Wea. Rev., 130, 1722-1748. 
McPherson, R. A., and K. K. Droegemeier, 1991: Numerical predictability experiments of the 20 May 1977 Del City, OK supercell storm. Preprints, Ninth Conf. on Numerical Weather Prediction, Denver, CO, Amer. Meteor. Soc., 734-738.

Nicholls, M. E., and R. A. Pielke, 1994a: Thermal compression waves. I: Total-energy transfer. Quart. J. Roy. Meteor. Soc., 120, 305-332.

— justment and vertical transfer of total energy. Quart. J. Roy. Meteor. Soc., 120, 333-359.

— gravity waves generated by convective storms. J. Atmos. Sci., 57, 3251-3271.

— - — , and W. R. Cotton, 1991: Thermally forced gravity waves in an atmosphere at rest. J. Atmos. Sci., 48, 1869-1884.

Pandya, R. E., and D. R. Durran, 1996: The influence of convectively generated thermal forcing on the mesoscale circulation around squall lines. J. Atmos. Sci., 53, 2924-2951.

Park, S. K., and K. K. Droegemeier, 2000: Sensitivity analysis of a 3D convective storm: Implications for variational data assimilation and forecast error. Mon. Wea. Rev., 128, 184-197.

Przybylinski, R. W., 1995: The bow echo: Observations, numerical simulations, and severe weather detection methods. Wea. Forecasting, 10, 203-218.

Qiu, C.-J., and Q. Xu, 1996: Least squares retrieval of microburst winds from single-Doppler radar data. Mon. Wea. Rev., 124, 1132-1144

Richardson, Y., 1999: The influence of horizontal variations in vertical shear and moisture on numerically-simulated convective storms. Ph.D. dissertation, University of Oklahoma, 236 pp.

Shapiro, A., S. Ellis, and J. Shaw, 1995: Single Doppler velocity retrievals with Phoenix II data: Clear air and microburst wind retrievals in the planetary boundary layer. J. Atmos. Sci., 52, 1265-1285.

Skamarock, W. C., and J. B. Klemp, 1992: The stability of timesplitting numerical methods for hydrostatic and nonhydrostatic elastic equations. Mon. Wea. Rev., 120, 2109-2127.

— and _ 1994: Efficiency and accuracy of the Klemp-Wilhelmson time splitting technique. Mon. Wea. Rev., 122, 2623 2630.

Smagorinsky, J., K. Miyakoda, and R. Strickler, 1970: The relative importance of variables in initial conditions for dynamical weather prediction. Tellus, 22, 141-154.

Snyder, C., and F. Zhang, 2003: Assimilation of simulated Doppler radar observations with an ensemble Kalman filter. Mon. Wea. Rev., 131, 1663-1677.

Sotack, T., and P. R. Bannon, 1999: Lamb's adjustment for heating of finite duration. J. Atmos. Sci., 56, 71-81.

Sun, J., and N. A. Crook, 1997: Dynamical and microphysical retrieval from Doppler radar observations using a cloud model and its adjoint. Part I: Model development and simulated data experiments. J. Atmos. Sci., 54, 1642-1661.

— , and - 1998: Dynamical and microphysical retrieval from Doppler radar observations using a cloud model and its adjoint. Part II: Retrieval experiments of an observed Florida convective storm. J. Atmos. Sci., 55, 835-852.

— , and —, 2001: Real-time low-level wind and temperature analysis using single WSR-88D data. Wea. Forecasting, 16, 117-132.

, D. W. Flicker, and D. K. Lilly, 1991: Recovery of threedimensional wind and temperature fields from simulated single-Doppler radar data. J. Atmos. Sci., 48, 876-890.
Tong, M., and M. Xue, 2005: Ensemble Kalman filter assimilation of Doppler radar data with a compressible nonhydrostatic model: OSSE experiments. Mon. Wea. Rev., 133, 1789-1807.

van Delden, A., 2000: Linear dynamics of hydrostatic adjustment to horizontally homogeneous heating. Tellus, 52A, 380-390.

Wakimoto, R. M., 2001: Convectively driven high wind events. Severe Convective Storms, Meteor. Monogr., No. 50, Amer. Meteor. Soc., 255-298.

Weisman, M. L., 1993: The genesis of severe, long-lived bow echoes. J. Atmos. Sci., 50, 645-670.

_ 2001: Bow echoes: A tribute to T. T. Fujita. Bull. Amer. Meteor. Soc., 82, 97-116.

_ simulated convective storms on vertical wind shear and buoyancy. Mon. Wea. Rev., 110, 504-520.

Weygandt, S. S., P. Nutter, E. Kalnay, S. K. Park, and K. K. Droegemeier, 1999: The relative importance of different data fields in a numerically-simulated convective storm. Preprints, Eighth Conf. on Mesoscale Processes, Boulder, CO, Amer. Meteor. Soc., 310-315.

—, A. Shapiro, and K. K. Droegemeier, 2002a: Retrieval of model initial fields from single-Doppler observations of a supercell thunderstorm. Part I: Single-Doppler velocity retrieval. Mon. Wea. Rev., 130, 433-453.

$\_, \ldots$, and — 2002b: Retrieval of model initial fields from single-Doppler observations of a supercell thunderstorm. Part II: Thermodynamic retrieval and numerical prediction. Mon. Wea. Rev., 130, 454-476.

Xue, M., K. K. Droegemeier, and V. Wong, 2000: The Advanced Regional Prediction System (ARPS) - A multi-scale nonhydrostatic atmospheric simulation and prediction model. Part I: Model dynamics and verification. Meteor. Atmos. Phys., 75, 161-193.

— , and Coauthors, 2001: The Advanced Regional Prediction System (ARPS) - A multi-scale nonhydrostatic atmospheric simulation and prediction model. Part II: Model physics and applications. Meteor. Atmos. Phys., 76, 143-165.

-, D. Wang, J. Gao, K. Brewster, and K. K. Droegemeier, 2003: The Advanced Regional Prediction System (ARPS), storm-scale numerical weather prediction and data assimilation. Meteor. Atmos. Phys., 78, 139-170.

- M. Tong, and K. K. Droegemeier, 2006: An OSSE framework based on the ensemble square-root Kalman filter for evaluating impact of data from radar networks on thunderstorm analysis and forecast. J. Atmos. Oceanic Technol., 23, $46-66$.

Yang, M.-J., and R. A. Houze Jr., 1995a: Multicell squall-line structure as a manifestation of vertically trapped gravity waves. Mon. Wea. Rev., 123, 641-661.

_ , and _ 1995b: Sensitivity of squall line rear inflow to ice microphysics and environmental humidity. Mon. Wea. Rev., 123, 3175-3193.

Zhang, F., C. Snyder, and J. Sun, 2004: Impacts of initial estimate and observation availability on convective-scale data assimilation with an ensemble Kalman filter. Mon. Wea. Rev., 132, 1238-1253.

Ziegler, C. L., 1985: Retrieval of thermal and microphysical variables in observed convective storms. Part I: Model development and preliminary testing. J. Atmos. Sci., 42, 1487-1509.

_ 1988 : Retrieval of thermal and microphysical variables in observed convective storms. Part II: Sensitivity of cloud processes to variation of the microphysical parameterization. $J$. Atmos. Sci., 45, 1072-1090. 